\title{
Cryptococcus neoformans Secretes Small Molecules That Inhibit IL-1 $\beta$ Inflammasome-Dependent Secretion
}

\author{
Pedro Henrique Bürgel, ${ }^{1,2}$ Clara Luna Marina, ${ }^{1}$ Pedro H. V. Saavedra, ${ }^{3}$ \\ Patrícia Albuquerque (iD, ${ }^{4,5}$ Stephan Alberto Machado de Oliveira, ${ }^{1}$ \\ Paulo Henrique de Holanda Veloso Janior, ${ }^{1}$ Raffael Araújo de Castro, ${ }^{1}$ Heino M. Heyman, ${ }^{6,7}$ \\ Carolina Coelho, ${ }^{8,9}$ Radames J. B. Cordero, ${ }^{8}$ Arturo Casadevall, ${ }^{8}$ Joshua D. Nosanchuk, ${ }^{10}$ \\ Ernesto S. Nakayasu, ${ }^{6}$ Robin C. May, ${ }^{2}$ Aldo Henrique Tavares $(D, 5$ \\ and Anamelia Lorenzetti Bocca ${ }^{1}{ }^{1}$
}

${ }^{1}$ Laboratory of Applied Immunology, Department of Cellular Biology, Institute of Biological Sciences, University of Brasília, Brazil

${ }^{2}$ Institute of Microbiology and Infection and School of Biosciences, University of Birmingham, Edgbaston, UK B15 2TT

${ }^{3}$ Immunology Program, Sloan Kettering Institute, Memorial Sloan Kettering Cancer Center, New York, NY, USA

${ }^{4}$ Laboratory of Molecular Biology of Pathogenic Fungi, University of Brasilia, Brasilia, Brazil

${ }^{5}$ Faculty of Ceilândia, University of Brasília, Brazil

${ }^{6}$ Biological Sciences Division, Pacific Northwest National Laboratory, Richland, Washington, USA

${ }^{7}$ Bruker Daltonics Inc., Billerica, MA, USA

${ }^{8}$ Department of Molecular Microbiology and Immunology, Johns Hopkins Bloomberg School of Public Health, Baltimore, MD, USA

${ }^{9}$ Medical Research Council Centre for Medical Mycology, College of Medicine and Health, University of Exeter and University of Aberdeen, Aberdeen, UK

${ }^{10}$ Departments of Medicine (Division of Infectious Diseases) and Microbiology and Immunology, Albert Einstein College of Medicine, Bronx, NY, USA

Correspondence should be addressed to Aldo Henrique Tavares; atavares@unb.br and Anamelia Lorenzetti Bocca; albocca@unb.br

Received 9 July 2020; Revised 22 October 2020; Accepted 4 November 2020; Published 7 December 2020

Academic Editor: Young-Su Yi

Copyright ( 2020 Pedro Henrique Bürgel et al. This is an open access article distributed under the Creative Commons Attribution License, which permits unrestricted use, distribution, and reproduction in any medium, provided the original work is properly cited.

Cryptococcus neoformans is an encapsulated yeast that causes disease mainly in immunosuppressed hosts. It is considered a facultative intracellular pathogen because of its capacity to survive and replicate inside phagocytes, especially macrophages. This ability is heavily dependent on various virulence factors, particularly the glucuronoxylomannan (GXM) component of the polysaccharide capsule. Inflammasome activation in phagocytes is usually protective against fungal infections, including cryptococcosis. Nevertheless, recognition of $C$. neoformans by inflammasome receptors requires specific changes in morphology or the opsonization of the yeast, impairing proper inflammasome function. In this context, we analyzed the impact of molecules secreted by $C$. neoformans B3501 strain and its acapsular mutant $\Delta$ cap67 in inflammasome activation in an in vitro model. Our results showed that conditioned media derived from B3501 was capable of inhibiting inflammasome-dependent events (i.e., IL$1 \beta$ secretion and LDH release via pyroptosis) more strongly than conditioned media from $\Delta$ cap 67 , regardless of GXM presence. We also demonstrated that macrophages treated with conditioned media were less responsive against infection with the virulent strain H99, exhibiting lower rates of phagocytosis, increased fungal burdens, and enhanced vomocytosis. Moreover, we showed that the aromatic metabolite DL-Indole-3-lactic acid (ILA) and DL-p-Hydroxyphenyllactic acid (HPLA) were present in B3501's conditioned media and that ILA alone or with HPLA is involved in the regulation of inflammasome activation by $C$. neoformans. These results were confirmed by in vivo experiments, where exposure to conditioned media led to higher fungal burdens in Acanthamoeba castellanii culture as well as in higher fungal loads in the lungs of infected mice. Overall, the results presented show that conditioned media from a wild-type strain can inhibit a vital recognition pathway and subsequent 
fungicidal functions of macrophages, contributing to fungal survival in vitro and in vivo and suggesting that secretion of aromatic metabolites, such as ILA, during cryptococcal infections fundamentally impacts pathogenesis.

\section{Introduction}

Cryptococcus neoformans is a fungal pathogen that primarily affects immunocompromised patients with acquired immunodeficiency syndrome (AIDS) [1]. C. neoformans is responsible for over 180 thousand deaths yearly worldwide [2]. Human infection is usually initiated by the inhalation of environmental spores or yeasts that are present in environmental sources [3-7]. Once in the lung, the fungus is cleared by the host or survives within granulomas. In the context of immunosuppression, primary acquisition or relapse of previously contained yeast can result in disseminated disease, especially involving the central nervous system $[5,8,9]$.

The ability of $C$. neoformans to remain viable and survive inside the host is dependent on its many virulence factors, which allow the fungus to modulate and evade the immune response [10, 11]. These virulence factors include enzymes (laccase, urease, phospholipases, proteases, and others) that can be secreted freely or encapsulated in extracellular vesicles $[10,12-14]$, melanin deposition in the cell wall $[14,15]$, and the formation of capsular polysaccharides, which are considered the most important of these factors [16-18]. Glucuronoxylomannan (GXM) is the most prevalent of these capsular polysaccharides, facilitating C. neoformans resistance against phagocytosis and suppressing various immune responses [19-26]. Altogether, these virulence factors enable this fungus to effectively survive and thrive as a facultative intracellular pathogen, particularly within macrophages [27-33]. Depletion of alveolar macrophages in mice is associated with a worse prognosis during infection with a glucosylceramide mutant, indicating that they might be co-opted by C. neoformans during pathogenesis to facilitate fungal growth and dissemination [34]. Phagocytic cells that are unable to kill intracellular yeast cells can return fungal cells to the extracellular environment, either through nonlytic exocytosis called vomocytosis [35-38] or a rapid, highly inflammatory and inflammasome-dependent cell death referred to as pyroptosis [39-41].

The inflammasome is an intracellular multiprotein complex that usually requires an intracellular damageassociated molecular pattern (DAMP) for its oligomerization and proper function [42]. The canonical activation step requires the engagement of an intracellular receptor from the NOD-like receptor (NLR) or AIM2-like receptor (ALR) family, an adaptor protein ASC and the cleavage of procaspase-1. Although some cell types can activate inflammasome pathways from basal expression levels, most of them require extracellular signaling, promoted by membrane-bound pattern-recognition receptors, to initiate inflammasome activation [43]. The activated caspases in this context are responsible for the previously described pyroptosis cell death and, most importantly, for the processing of interleukin- (IL-) $1 \beta$ and IL-18, essential mediators of inflammatory Th1/Th17-driven responses [44].
Among the receptors associated with inflammasome oligomerization, NLRP3 is one of the best described and well characterized in fungal recognition [45]. This receptor is involved in recognition of various fungal species, between yeast and hyphal forms, and opportunistic and primary pathogens [46-51]. The activation of NLRP3 is usually dependent on one or more intracellular stress signals (i.e., potassium efflux; mitochondrial reactive oxygen species production and cathepsin release), which are associated with the interaction between the host cell and the fungus [42, 45]. NLRP3 activation in response to $C$. neoformans only occurs when the yeast is in specific conditions such as biofilms [52], lacking capsule [53], or opsonized before phagocytosis [54]. Moreover, all three classical stress signals are required to activate NLRP3 during these interactions [52]. Notably, mice lacking NLRP3 or ASC are more susceptible to cryptococcal infection with encapsulated yeast cells, whereas infection with acapsular yeast cells results in higher fungal burdens in the lungs in NLRP3 knockout mice [52, 53]. Likewise, susceptibility to cryptococcal infection has also been observed in murine knockout models for IL- $1 \beta$ and IL-18 receptors $[55,56]$.

Different strains of $C$. neoformans elicit variable IL- $1 \beta$ induction, especially in in vitro models. Although GXM participates in inflammasome inhibition when macrophages are challenged with acapsular strains [53], capsule-independent inhibition of the inflammasome remains poorly understood. Here, we show that other secreted molecules besides GXM can specifically interfere with intracellular signals during inflammasome activation, suppressing various processes associated with this activation and reducing the overall antifungal capacity of macrophages. Furthermore, we have defined two molecules presents in C. neoformans conditioned media that participate in inhibiting inflammasome activation in the presence of this remarkable fungus.

\section{Material and Methods}

2.1. Ethics Statement. All experimental procedures were approved by the Animal Ethics Committee of the University of Brasilia (UnBDoc number 55924/2016) and conducted according to the Brazilian Council for the Control of Animal Experimentation (CONCEA) guidelines.

2.2. Fungal Strains. Cryptococcal species complex strains H99 (var. grubii/Cryptococcus neoformans), B3501 (var. neoformans/Cryptococcus deneorformans), and cap67 (acapsular strain derived from B3501) were grown for $18 \mathrm{~h}$ in Sabouraud dextrose broth, rotating $(120 \mathrm{rpm})$ at $30^{\circ} \mathrm{C}$. Yeast cells were retrieved from culture by centrifugation ( $5 \mathrm{~min}, 1800 \mathrm{~g}$ ) and washed twice in PBS before experiments.

2.3. Conditioned Medium, GXM Isolation, and Subsequent Treatments. B3501 and cap67 strains were grown for 5 days in minimal media (MM) (glucose $15 \mathrm{mM}$, magnesium sulfate $10 \mathrm{mM}$, monopotassium phosphate $29.4 \mathrm{mM}$, glycine 
$13 \mathrm{mM}$, and thiamine $3 \mu \mathrm{M})$ rotating $(120 \mathrm{rpm})$ at $30^{\circ} \mathrm{C}$ [57]. Yeast cells were removed from culture by centrifugation $(2 \times 15 \mathrm{~min} 5500 \mathrm{~g})$. The supernatant was collected and filtered $(0.45 \mu \mathrm{m})$ for complete yeast removal. The filtrate was lyophilized and suspended in deionized water, with a tenfold concentration. The products obtained from the B3501 and $\Delta$ cap67 strains were denominated conditioned media 35 (CM35) and conditioned media CAP (CMCAP), respectively [58]. CM35 was treated and/or fractioned for subsequent experiments. The size fractions were obtained utilizing an ultrafiltration Amicon system (Millipore), with filtration membranes varying from 100 to 1 kilodalton $(\mathrm{kDa})$. In between fractions (e.g., $100 \mathrm{kDa}>\mathrm{CM} 35>10 \mathrm{kDa}$ ) were also obtained, by recovering molecules retained in the filtration membrane. Polarity fractions were obtained by Blight-Dyer technique. Additionally, CM35 was treated by autoclaving $\left(20 \mathrm{~min}\right.$ at $\left.123^{\circ} \mathrm{C}\right)$ and with the following proteases $(24 \mathrm{~h}$ at $37^{\circ} \mathrm{C}$ ): trypsin, thermolysin, and pronase. CM35 was also processed to remove GXM using a GXM-capture enzymelinked immunosorbent assay (ELISA), as described by Rodrigues et al. [59]. Briefly, an ELISA high-binding plate was coated with mAb 18B7 (a monoclonal antibody $(\mathrm{Ab}$ ) specific for GXM) [60] for $2 \mathrm{~h}$ at room temperature, preceded by a blocking step with $1 \%$ BSA solution for $1 \mathrm{~h}$. Finally, conditioned media or minimal media were added to the wells for an additional $2 \mathrm{~h}$ and recovered at the end. The bound GXM was recovered by elution with Tris-glycine ( $\mathrm{pH} 7.4)$ buffer. Yeast capsular polysaccharides from B3501 were harvested [61] and kindly supplied by Julie M. Wolf (Albert Einstein College of Medicine). Exopolysaccharides were obtained by the collection of a viscous layer in the $10 \mathrm{kDa}$ membrane during CM35 ultrafiltration, as described [62].

\subsection{Polysaccharide (PS) Attachment and} Immunofluorescence. Polysaccharide (PS) attachment to $\Delta c a p 67$ cell wall was performed as described [63]. $\Delta$ cap67 cells were incubated in yeast-free B3501 conditioned medium (grown in a minimal medium for 4 days) overnight at $37^{\circ} \mathrm{C}$. B3501, $\Delta c a p 67$, and $\Delta c a p 67-P S$ were fixed with $4 \%$ paraformaldehyde for 30 minutes at room temperature and incubated with PBS $+1 \%$ bovine serum albumin for $1 \mathrm{~h}$ at room temperature. Yeast cells were then incubated with $0.01 \%$ Uvitex2B (a chitin marker; Polysciences) and mAb $18 \mathrm{~B} 7$ $(10 \mu \mathrm{g} / \mathrm{ml})$ for 30 minutes followed by incubation with Alexa Fluor 546 anti-mouse IgG1 $(5 \mu \mathrm{g} / \mathrm{ml}$; Invitrogen) for 30 minutes at $37^{\circ} \mathrm{C}$. Cells were then suspended in an antifading agent, mounted on glass slides, and analyzed with a confocal microscope (Leica TCS SP5).

2.5. Generation of Bone Marrow-Derived Macrophages (BMDMs and BMMs) and Dendritic Cells (BMDCs). Bone marrow cells were obtained from C57BL/6 isogenic mice (8-10 weeks old), as previously described [49]. Briefly, femurs and tibias were flushed with RPMI-1640 to harvest the bone marrow cells. Cells were submitted to erythrocyte lysis under a Tris-buffered ammonium chloride solution, seeded $\left(2 \times 10^{5}\right.$ cells $\left./ \mathrm{ml}\right)$, and cultured for 8 days at $37^{\circ} \mathrm{C}$ in non-tissue culture-treated Petri dishes in $10 \mathrm{ml} /$ dish of RPMI-1640 medium that contained $50 \mathrm{mM}$ 2-mercapto- ethanol. The medium was supplemented with $20 \mathrm{ng} / \mathrm{ml}$ murine granulocyte-macrophage colony-stimulating factor (GM-CSF, PeproTech) to obtain BMDCs and BMDMs or $30 \%$ conditioned medium from macrophage colonystimulating factor-secreting L929 fibroblasts (M-CSF) to obtain BMMs. On the third day, an additional $10 \mathrm{ml}$ of a complete medium that contained differentiation-inducing cytokines was added. Half the medium was exchanged on the sixth day of culturing the BMDCs. On the eight-day, non- and loosely adherent BMDCs or firmly adherent BMMs were stripped with TrypLE ${ }^{\mathrm{TM}}$ Express (Gibco), harvested, and plated in RPMI-1640 medium supplemented with Fetal Bovine Serum (FBS) and gentamicin.

2.6. Murine Cell Culture Interaction with Conditioned Media. BMMs or BMDCs $\left(1 \times 10^{6} / \mathrm{ml}\right)$ were incubated at $37^{\circ} \mathrm{C}$ in a humidified $5 \% \mathrm{CO}^{2}$ atmosphere. Cells were stimulated with lipopolysaccharide (LPS; $500 \mathrm{ng} / \mathrm{ml}$ for $4 \mathrm{~h}$, Sigma-Aldrich), providing the first signal for inflammasome activation. Additionally, cells were incubated for $18 \mathrm{~h}$ with or without potential inhibitors: CM35 (and its fractions), CMCAP, minimal medium, glycine (Sigma-Aldrich), glucuronoxylomannan (GXM), and aromatic metabolites: (Sigma) 3-Phenyllactic acid (PLA); DL-p-Hydroxyphenyllactic acid (HPLA) and DL-Indole-3-lactic acid (ILA), alone or in combination. After that, cells were treated with nigericin $(20 \mu \mathrm{M}$ for 40 or 90 minutes, InvivoGen), providing the second signal for inflammasome activation. Alternatively, cells stimulated with LPS were infected with the fungal strains opsonized with $\mathrm{mAb}$ 18 B7 (a kind gift from A. Casadevall, Johns Hopkins Bloomberg School of Public Health) [60]. Controls included conditions without LPS or nigericin.

2.7. Cytokine Quantification by ELISA and Lactate Dehydrogenase (LDH) Detection. The cell-free supernatants of the BMM and BMDC cultures were harvested for measurements of IL-1 $\beta$ and tumor necrosis factor- (TNF-) $\alpha$ (Ready-Set-Go! Kit, eBioscience) concentrations using ELISA. The determination of intracellular pro-IL-1 $\beta$ was performed with the cell lysates (Ready-Set-Go! Kit, eBioscience). The data were expressed as $\mathrm{pg} / \mathrm{ml} \pm$ the standard deviation (SD) of two to three independent experiments, which were conducted in triplicate.

The cell-free supernatants of the BMM cultures were harvested to quantify LDH release, as a cell death marker (CytoTox $96{ }^{\circledR}$ Non-Radioactive Cytotoxicity Assay, Promega) after treatment with nigericin for 90 minutes. The data were expressed as percentage \pm the standard deviation (SD) of two to three independent experiments, which were conducted in triplicate, considering cells without any treatment as $0 \%$ and cells treated with $15 \%$ dimethyl sulfoxide (DMSO) as $100 \%$ of cell death.

2.8. Active Caspase-1 Detection by Flow Cytometry. BMMs challenged with $C$. neoformans strains (MOI 5:1) opsonized with $\mathrm{mAb} 18 \mathrm{~B} 7$ were harvested from the tissue culture well plates with a dissociation agent (TrypLE Express, Thermo Fisher Scientific). $5 \times 10^{5}$ were collected per group before staining. Staining for caspase-1 (FAM-FLICA ${ }^{\text {TM }}$ Caspase-1 
Assay Kit, Immunochemistry) was performed according to the manufacturer's instructions. The cells were then analyzed in a flow cytometer (FACSVerse, BD Biosciences) with the FITC filter channel (FL-1), and data were processed (FlowJo $\mathrm{X}, \mathrm{LLC})$.

2.9. cDNA Synthesis and Real-Time Reverse Transcription Polymerase Chain Reaction (RT-PCR). Total RNA from the cultured BMDMs was extracted using TRIzol reagent (Invitrogen), and cDNA synthesis was performed using a highcapacity RNA-to-cDNA kit (Applied Biosystems), according to the manufacturer's instructions. qRT-PCR was performed using SYBR Green Master Mix and StepOne Real-Time PCR System (Applied Biosystems). The primer sequences were as follows: IL- $1 \beta$ forward, $5^{\prime}$-GTGTGTGACGTTCCCATTA GACA- $3^{\prime}$; IL- $1 \beta$ reverse, $5^{\prime}$-CAGCACGAGGCTTTTTTGT TG-3'; Nf- $\kappa$ B forward, $5^{\prime}$-AGCCAGCTTCCGTGTTTGT $\mathrm{T}-3^{\prime}$; nuclear factor kappa-light-chain-enhancer of activated $\mathrm{B}$ cells (Nf- $\kappa \mathrm{B})$ reverse, $5^{\prime}$-AGGGTTTCGGTTCACTAGT TTCC- $3^{\prime}$; GAPDH forward, $5^{\prime}$-TGAAGCAGGCATCTGA GGG-3'; glyceraldehyde 3-phosphate dehydrogenase $(\mathrm{GAPDH})$ reverse, $5^{\prime}$-CGAAGGTGGAAGAGTGGGAG-3' ; IL- $1 \beta$ or Nf- $\kappa$ B to GAPDH relative expression was calculated using the $2^{(-\mathrm{ct})}$ method and normalized to the level of unstimulated BMMs.

2.10. Vomocytosis Scoring by Flow Cytometry. BMMs challenged with stained H99 with Calcofluor White $(10 \mu \mathrm{g} / \mathrm{ml}$, $10 \mathrm{~min}$, Sigma-Aldrich) were treated concomitantly with CM35 or left untreated [64]. After $2 \mathrm{~h}$ of interaction, all wells were gently washed three times with warm PBS. The last wash from the $2 \mathrm{~h}$ time point wells were collected, and the cells were lysed. RPMI with fluconazole $(10 \mu \mathrm{g} / \mathrm{ml}$, SigmaAldrich) was added in the other wells, and the cells were treated again with CM35 or left untreated. The supernatant and cell lysate were collected in determined time points (6, 12, and $24 \mathrm{~h})$. Right after the collection, both supernatant and lysate samples were centrifuged $(2.000 \times \mathrm{g}, 5 \mathrm{~min})$ for yeast recovery and fixated in paraformaldehyde $4 \%$ in PBS until flow cytometry analysis. Samples were accessed by flow cytometry (FACS Fortessa, BD Biosciences), at low-speed acquisition for 4 minutes. Parent yeast cells were detected using a high Calcofluor fluorescence gate. Using the specification provided by the manufacturer, the number of yeast $/ \mathrm{ml}$ was calculated.

2.11. Coincubation Assays (Phagocytic Index, Fungicidal Activity, and Transwell Assays). BMMs were challenged with H99 opsonized with mAb 18B7 (MOI 2:1), and the phagocytosis rates and fungal burdens were analyzed at $37^{\circ} \mathrm{C}$. For the phagocytosis assay, BMDMs were primed with LPS (500 $\mathrm{ng} / \mathrm{ml}$ ) for $4 \mathrm{~h}$ followed by treatment overnight with conditioned media. Controls were left untreated. After this period, the cells were challenged with opsonized H99. After $2 \mathrm{~h}$, the wells were gently washed three times with warm PBS, and the remaining coculture was fixed and stained with modified Wright-Giemsa stain. The phagocytic index was calculated by multiplying the number of macrophages engag- ing phagocytosis and the number of yeasts phagocyted per 100 macrophages analyzed. For the yeast intracellular growth assay, BMMs primed with LPS $(500 \mathrm{ng} / \mathrm{ml})$ or not were challenged with opsonized H99 and concomitantly treated with conditioned media or left untreated. After $2 \mathrm{~h}$, all the wells were gently washed three times with warm PBS to remove extracellular yeast. Right after the washes as well as $24 \mathrm{~h}$ later, macrophages were lysed with $0.05 \%$ SDS and intracellular yeasts recovered and measured by colony forming units (CFU) by plating on Sabouraud dextrose agar. The intracellular growth rate was determined by dividing $2 \mathrm{~h}$ CFU by $24 \mathrm{~h}$ CFU. For the transwell assay, BMMs were seeded in both upper and lower chambers and primed with LPS $(500 \mathrm{ng} / \mathrm{ml})$. The BMMs in the lower chamber were challenged with opsonized Cryptococcus strains (MOI 5:1) or left uninfected, while the BMMs in the upper chamber were not challenged. After $24 \mathrm{~h}$ at $37^{\circ} \mathrm{C}$, macrophages from the upper chambers were challenged with opsonized green fluorescent protein (GFP) expressing H99 (MOI 2:1) and lysed with $0.05 \%$ sodium dodecyl sulfate SDS at $24 \mathrm{~h}$ postinfection. Alternatively, the lower chambers contained only yeast cells from Cryptococcus strains in a media with LPS $(500 \mathrm{ng} / \mathrm{ml})$ throughout the essay. The recovered intracellular yeast cells were quantified using flow cytometry.

2.12. Detection of GXM Internalization Using Fluorescence Microscopy. BMDMs primed with LPS were treated with CMCAP or CM35 and their fractioned derivatives, as described earlier. BMMs were plated in glass inserts, and after $18 \mathrm{~h}$ of interaction with conditioned media, cells were permeabilized and fixed with cold methanol (Vetec) for 10 minutes. After consecutive washes, cells were blocked for $1 \mathrm{~h}$ with a $10 \%$ FBS solution and stained for GXM with $\mathrm{mAb} 18 \mathrm{~B} 7(10 \mu \mathrm{g} / \mathrm{ml})$ as a primary $\mathrm{Ab}$ and "Alexa Fluor ${ }^{\circledR}$ 633 Goat Anti-Mouse IgG” (Life Technologies) as a secondary Ab. Cells were also stained with a DAPI solution (Life Technologies). The glass inserts were then recovered, and GXM content internalized by the BMMs was observed under a confocal microscope (Leica TCS SP5).

2.13. Gas Chromatography-Mass Spectrometry Analysis. Metabolites from conditioned culture media were derivatized as described [65]. Ketone groups of metabolites were derivatized by adding $20 \mu \mathrm{l}$ of $30 \mathrm{mg} / \mathrm{ml}$ methoxyamine in pyridine (Sigma-Aldrich) and incubating at $37^{\circ} \mathrm{C}$ for 90 minutes with shaking (1000 RPM). Then, amine, hydroxyl, and carboxyl groups were modified with $80 \mu \mathrm{l}$ of $\mathrm{N}$-methyl-N-(trimethylsilyl)trifluoroacetamide (MSTFA) (Sigma-Aldrich) with $1 \%$ trimethylchlorosilane (TMCS) (Sigma-Aldrich) by shaking $(1000 \mathrm{rpm})$ at $37^{\circ} \mathrm{C}$ for 30 minutes. Derivatized samples were analyzed in an Agilent GC 7890A using a HP-5MS column $(30 \mathrm{~m} \times 0.25 \mathrm{~mm} \times 0.25 \mu \mathrm{m}$; Agilent Technologies) coupled with a single quadrupole MSD 5975C (Agilent Technologies). Samples were injected in the splitless mode with the port temperature set at $250^{\circ} \mathrm{C}$ and oven temperature equilibrated at $60^{\circ} \mathrm{C}$. The oven temperature was kept at $60^{\circ} \mathrm{C}$ for 1 minute and then raised to $325^{\circ} \mathrm{C}$ at a rate of $10^{\circ} \mathrm{C} /$ minute and finally finished with 5 minutes hold at $325^{\circ} \mathrm{C}$. A fatty acid methyl ester (FAME) standard mix was analyzed with each 


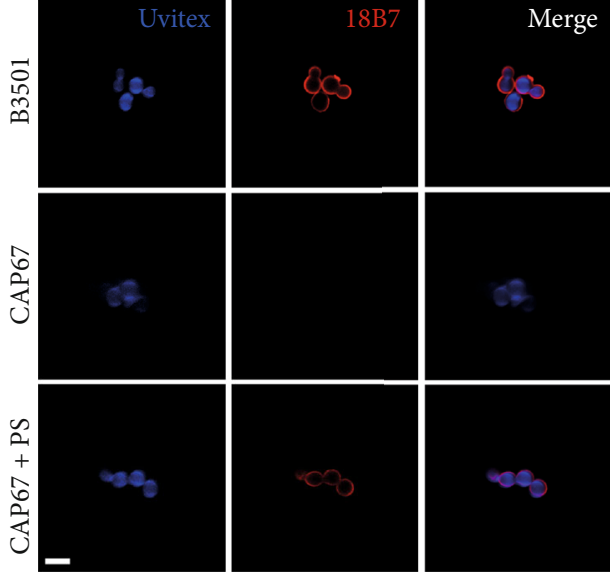

(a)

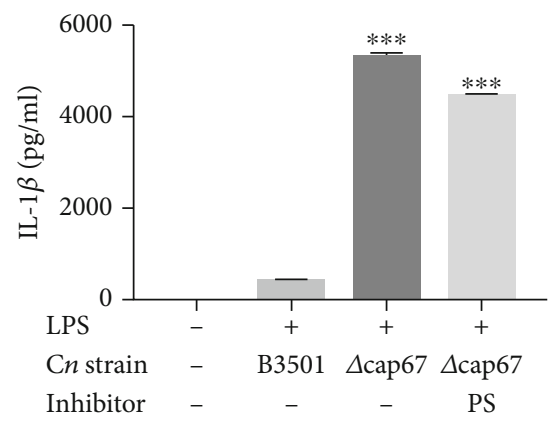

(b)

FIGURE 1: Exopolysaccharide incorporation on an acapsular mutant does not impair macrophage inflammasome activation. (a) GXM detection by immunofluorescence of B3501, CAP67 ( $\Delta$ cap67), and CAP67+PS ( $\Delta$ cap67 coated with polysaccharides from B3501) labeled with Uvitex2B (blue) and mAb against GXM (18B7) (red). (b) BMDMs were stimulated with LPS (500 ng/ml) and infected with opsonized B3501, $\Delta$ cap67, or $\Delta$ cap67+PS strains (MOI 2:1) for $24 \mathrm{~h}$. Statistical analysis was performed using one-way ANOVA, where *** $P \leq 0.001$. Comparisons were made with the B3501-infected group.

batch for subsequent retention time calibration purposes. Collected data files were processed with MetaboliteDetector [66], by calibrating retention indices (RI) based on FAME standards and deconvoluting and chromatographically aligning features. Metabolites were identified by matching spectral features and retention indices against a PNNL augmented version of the FiehnLib library containing more than 900 metabolites [67]. Unidentified metabolites were also searched against the NIST14 GC-MS library by comparing spectral features only. All identifications were manually validated. Extracted metabolite intensities were subjected to multivariate data analysis (MVDA) using MetaboAnalyst [68]. The data were median normalized and $\log$ transformed followed by principal component, hierarchical cluster, and heat map analysis to identify natural clustering within the data.

\subsection{Acanthamoeba Infection and Treatment with} Conditioned Media. Acanthamoeba castellanii was cultivated in liquid Yeast Peptone Dextrose Medium (YPD, $2 \%$ peptone, $1.8 \% \mathrm{D}$-glucose, $0.1 \%$ yeast extract) supplemented with $0.0034 \mathrm{M}$ tribasic sodium citrate, 0.004 sodium sulfate, $0.0025 \%$ monobasic sodium phosphate, $0.0025 \%$ monobasic potassium phosphate, $0.00005 \%$ iron ammonium sulfate hexahydrate, and $0.00004 \%$ calcium chloride dihydrate at $30^{\circ} \mathrm{C}$. A. castellanii $\left(5 \times 10^{5}\right.$ cells $\left./ \mathrm{ml}\right)$ and C. neoformans H99 $\left(1 \times 10^{6}\right.$ cells $\left./ \mathrm{ml}\right)$ were concomitantly added to culture plates with treatments $(10 \%$ of the volume): $\mathrm{PBS},<1 \mathrm{kDa} \mathrm{CM} 35$, minimal medium, or aromatic metabolites $(1 \mathrm{mM})$ : ILA alone or in combination with HPLA or with HPLA and PLA. After $24 \mathrm{~h}$, the cells were washed three times with PBS to withdraw any fungi not internalized by amoebas. To lysate the amoebas but not the yeasts, $0.01 \%$ Triton X-100 was added, and they were sonicated for 10 minutes. Afterward, the lysate was plated in Sabouraud agar plates, which were incubated for $48 \mathrm{~h}$ at $30^{\circ} \mathrm{C}$ for quantification of CFU.

\subsection{Murine Infection and Treatment with Conditioned} Media. The influence of CM treatment in the host immune response was analyzed using three groups of male $\mathrm{C} 57 \mathrm{Bl} / 6$ wild-type mice 8-12 weeks old infected with the virulent strain H99 of C. neoformans followed by treatment with $<1 \mathrm{kDa}$ CM35 or aromatic metabolites. Each group was formed with eight mice, and all of them were challenged with $8 \times 10^{4}$ cryptococcal cells by intratracheal inoculation. Before the surgery, animals were anesthetized following the instruction of Ethics Committee, injecting a solution of Ketamine-Vetnil and Xylazine-Ceva $(1: 1)$ in the intramuscular region of one of the hind paws of the mice. The volumes used for anesthesia were according to animal weight. Two and seven days after infection, each group received a treatment of $20 \mu \mathrm{l}$ of intranasal MM, PBS, $0<1 \mathrm{kDa}$ CM35, or ILA+HPLA $(1 \mathrm{mM})$. Fourteen days after infection, the mice were euthanized by hypoxia using a $\mathrm{CO}_{2}$ chamber, and the lungs and brain were surgically removed to the analysis of fungal burden and cytokine production. For quantification of fungal burden, the tissues obtained were weighed and macerated in $1 \mathrm{ml}$ of PBS using a glass macerator. The homogenized tissues were plated in a Sabouraud agar plate and incubated at $30^{\circ} \mathrm{C}$ for $48 \mathrm{~h}$, allowing the counting of CFU.

2.16. Statistical Analysis. Statistical analysis was conducted using GraphPad Prism v.7.0 software. Data were analyzed by one-way ANOVA followed by Tukey's post hoc test. $P$ values less than 0.05 were considered significant. The metabolomics assay was analyzed by $t$-test, PCA, and OPLS, and the metabolite figure was generated from an Excel spreadsheet that was extracted from a heat map using the $t$-test 


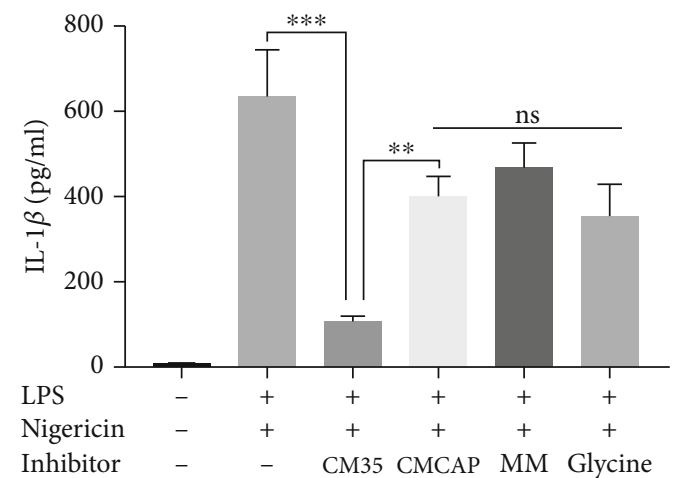

(a)

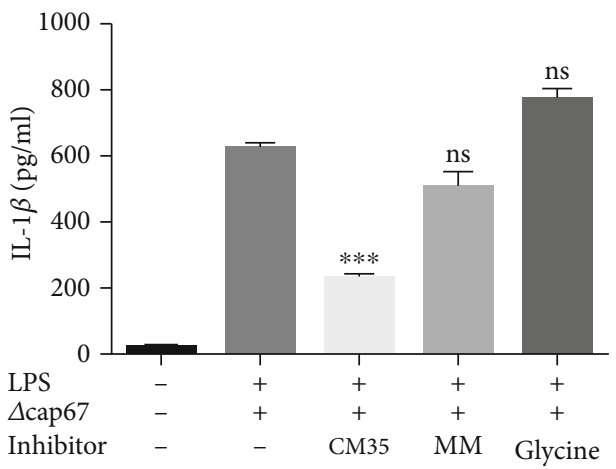

(c)

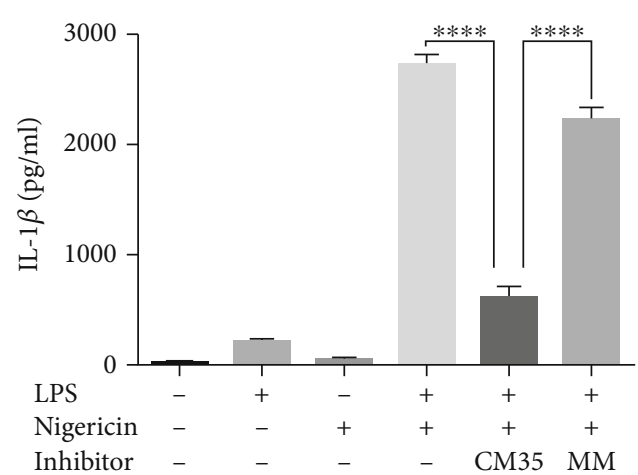

(b)

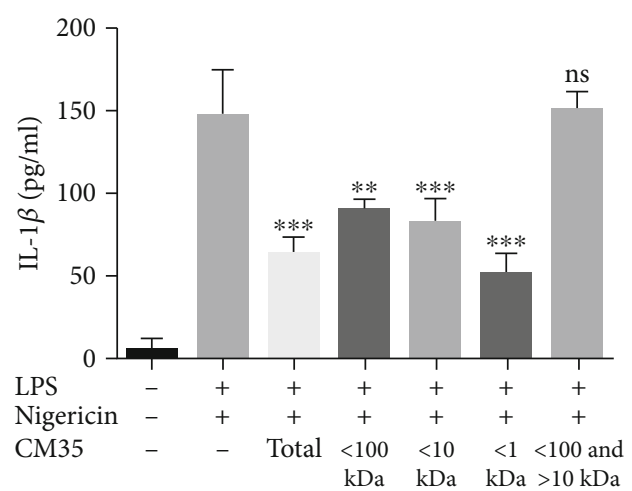

(d)

Figure 2: CM35, but not CMCAP or minimal media reduces IL- $1 \beta$ secretion. (a) BMMs were stimulated with LPS (500 ng/ml) and/or nigericin $(20 \mu \mathrm{M})$, added or not by mediums (CM35; CMCAP or MM 10\% v/v) or glycine (13 mM) overnight (18 h). (b) BMDCs were stimulated with LPS $(500 \mathrm{ng} / \mathrm{ml})$ and/or nigericin $(20 \mu \mathrm{M})$, added by media (CM35 or MM 10\% $v / v)$ overnight (18h). (c) BMDMs were stimulated with LPS ( $500 \mathrm{ng} / \mathrm{ml}$ ), infected with $\Delta$ cap67 strain (MOI 5:1), added or not by mediums (CM35 or MM $10 \% v / v)$ or glycine $(13 \mathrm{mM})$ overnight $(18 \mathrm{~h})$. (d) BMDMs stimulated with LPS $(500 \mathrm{ng} / \mathrm{ml})$ and/or nigericin $(20 \mu \mathrm{M})$, added by CM35 $>100 \mathrm{kDa},<100$ and $>10 \mathrm{kDa},<10 \mathrm{kDa}$ and $<1 \mathrm{kDa}(10 \% v / v)$ overnight $(18 \mathrm{~h})$. Supernatants were collected after stimulus and cytokines were quantified by ELISA technique. $\mathrm{CM} 35$ = conditioned media from B3501; CMCAP = conditioned media from $\Delta$ cap67; $\mathrm{MM}=$ minimal media. Statistical analysis was performed utilizing one-way ANOVA, where ns: not significant; ${ }^{* *} P \leq 0.002 ;{ }^{* * *} P \leq 0.001$. Comparisons were made with the positive control group (LPS+nigericin) when not indicated (c, d).

values. For normalization, the data were median centered and $\log$ transformed.

\section{Results}

3.1. Exopolysaccharide Incorporation on Acapsular Mutant Does Not Impair Macrophage Inflammasome Activation. As described previously [53,54], C. neoformans mutants lacking GXM expression and proper capsule formation triggered inflammasome activation more effectively than wild-type encapsulated yeast cells presumably due to the presence of immunomodulatory exopolysaccharides, including GXM, in the fungal capsule. However, we found that $\Delta c a p 67$ coated with exo-PS which consists mostly of GXM molecules (Figure 1(a)) induced significantly more IL-1 $\beta$ secretion compared to the wild-type B3501 (Figure 1(b)). This result suggested that the presence of GXM on the yeast surface by itself was not sufficient to explain the differences in inflammasome activation observed between acapsular mutants and their wild-type counterparts.
3.2. CM35, But Not CMCAP or Minimal Media, Reduces IL$1 \beta$ Secretion. Since many of the virulence factors presented by $C$. neoformans are secreted $[10,15]$, we evaluated whether components released by the fungus (CM) were able to inhibit inflammasome canonical activation. The addition of CM35 to activated macrophages (Figure 2(a)) and dendritic cells (Figure 2(b)) significantly reduced the secretion of IL- $1 \beta$ by these cells, while CMCAP, MM, and glycine inhibited IL- $1 \beta$ secretion to a lesser degree (Figures 2(a) and 2 (b), S1A Fig). Interestingly, CM35, CMCAP, and MM did not reduce the secretion of TNF- $\alpha$ (S1B-D Fig), even if added before LPS priming (S1E Fig). The same pattern was observed when conditioned media from $\mathrm{H} 99$ strain was used as treatment (S1G$\mathrm{H}$ Fig). The specific interference of conditioned media in the secretion of IL-1 $\beta$, an inflammasome-dependent cytokine, but not in TNF- $\alpha$, an inflammasome-independent cytokine, indicates that the canonical inflammasome pathway is being inhibited. The reduction in IL- $1 \beta$ observed with CMCAP and $\mathrm{MM}$ is likely explained by the presence of glycine (Figure 2(a)). We tested if the same results were found when using a different stimulus for inflammasome; we primed 


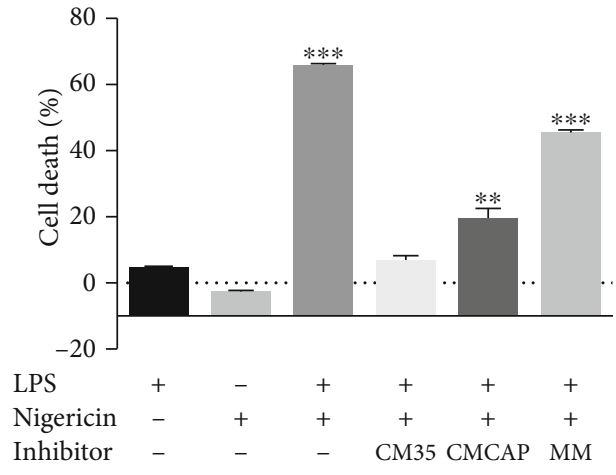

(a)

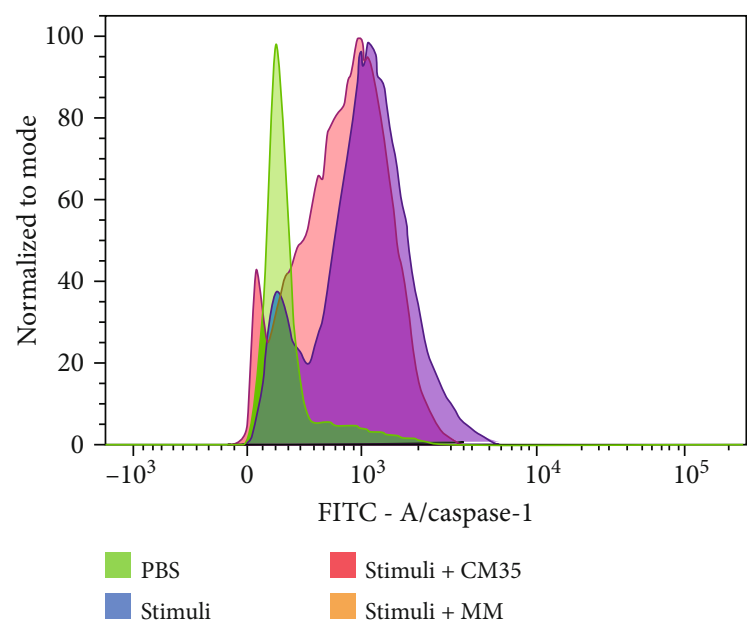

(c)

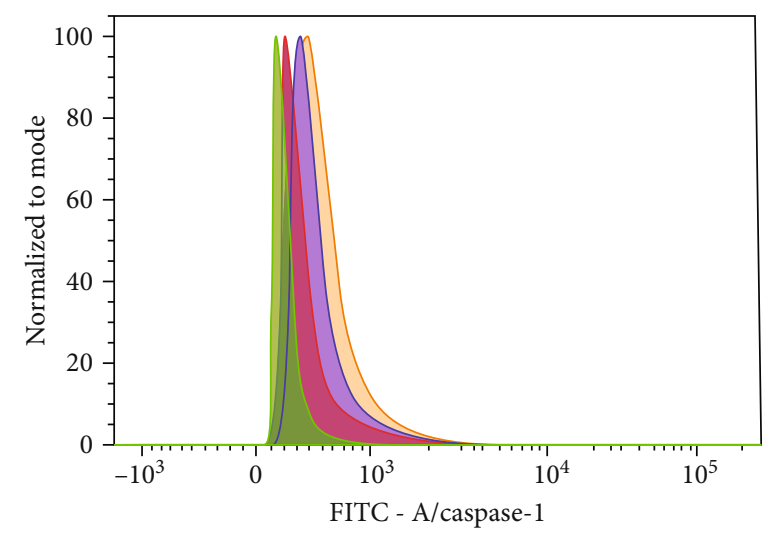

(e)

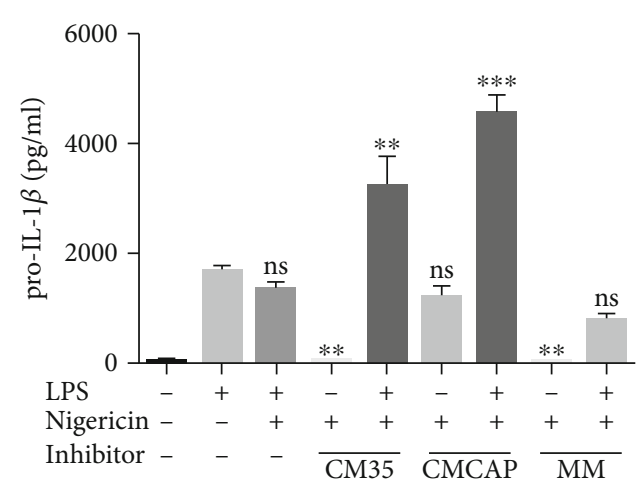

(b)

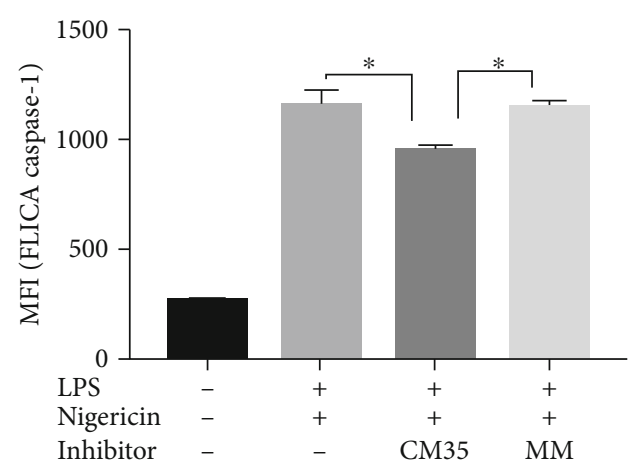

(d)

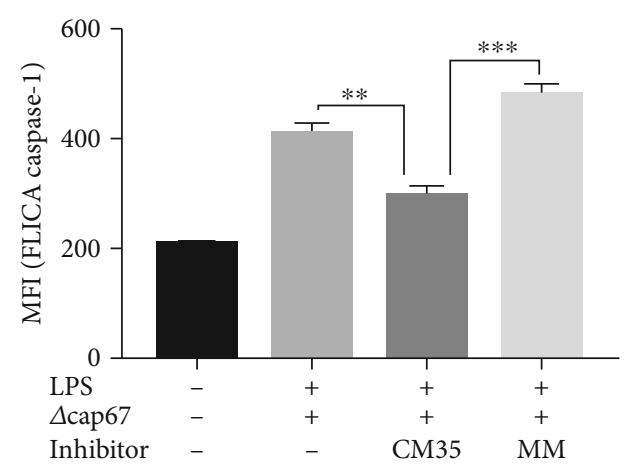

(f)

Figure 3: $1 \mathrm{kDa}$ CM35 inhibits caspase-1 activation, promotes pro-IL-1 $\beta$ accumulation, and inhibits cell death. (a) LDH release from supernatants of BMMs stimulated with LPS $(500 \mathrm{ng} / \mathrm{ml})$ and/or nigericin $(20 \mu \mathrm{M})$, with or without inhibitors $(10 \% v / v)$. The medium group was utilized as negative control ( $0 \%$ of cell death) and the DMSO (15\%) group was used as positive control (100\% of cell death). (b) pro-IL- $1 \beta$ production measured from cell lysates of BMMs stimulated with LPS $(500 \mathrm{ng} / \mathrm{ml})$ and/or nigericin $(20 \mu \mathrm{M})$, with or without inhibitors $(10 \% v / v)$. (c-f) BMMs stimulated with LPS $(500 \mathrm{ng} / \mathrm{ml})$ and nigericin $(20 \mu \mathrm{M})$ or $\Delta$ cap67 (MOI $5: 1)$, with or without inhibitors, were analyzed for caspase- 1 activation (FLICA). LDH release was measured by colorimetric assay (a), cytokine was measured by ELISA (b), and caspase activation was measured by flow cytometry. (c, d) LPS and nigericin or (e, f) Cap67 was used as stimuli, and the mean fluorescence intensity (MFI) was assessed (d, f). Statistical analysis was performed by one-way ANOVA, where ns: not significant; ${ }^{*} P \leq 0.033 ;{ }^{* *} P \leq 0.002 ;{ }^{* * *} P \leq 0.001$. Comparisons were made with the LPS only group $(\mathrm{a}, \mathrm{b})$.

macrophages with LPS followed by challenging with the acapsular strain $\Delta$ cap67. In these conditions, BMMs still show a marked reduction in IL- $1 \beta$ levels in the presence of
CM35, while in these conditions $\mathrm{MM}$ and glycine did not affect IL- $1 \beta$ secretion (Figure $2(\mathrm{c})$ ), indicating that CM35 is able to decrease the inflammasome activation in the context 


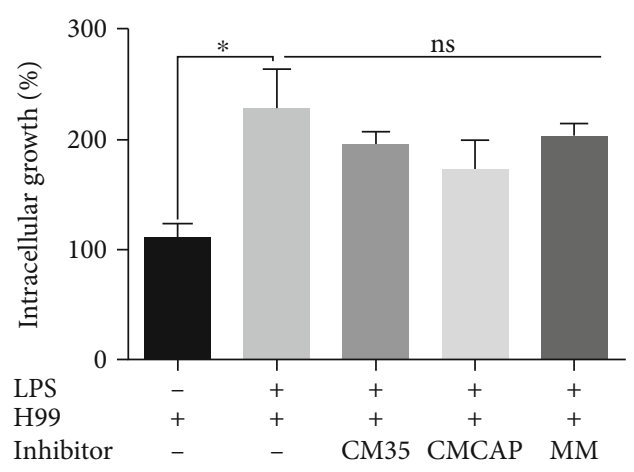

(a)

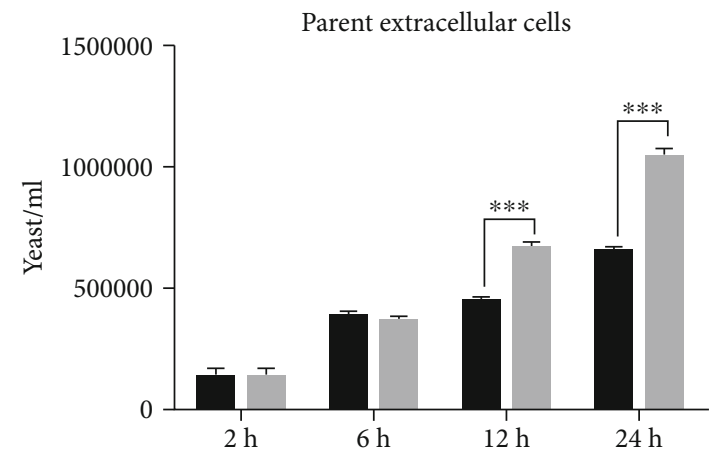

- PBS + fluconazole

CM35 + fluconazole

(c)

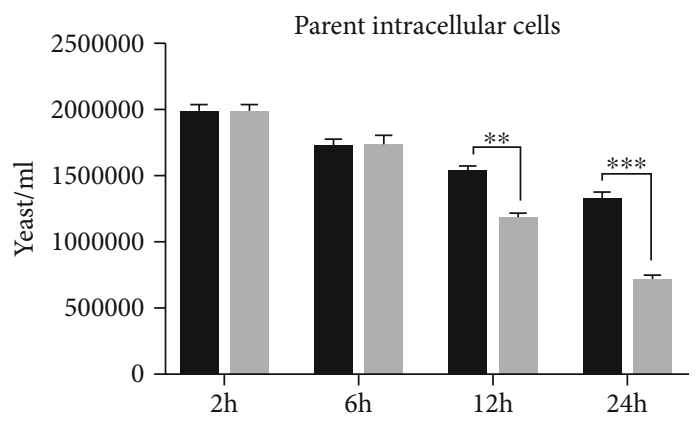

(e)

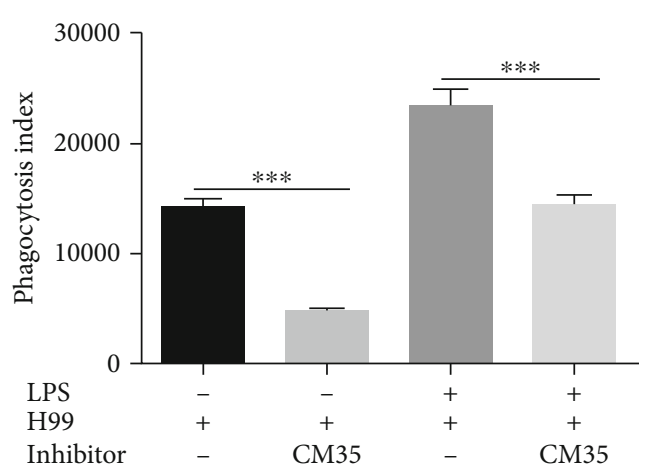

(b)

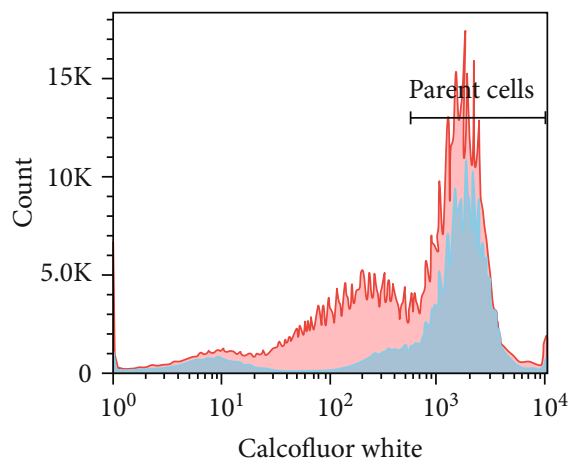

PBS

CM35

(d)

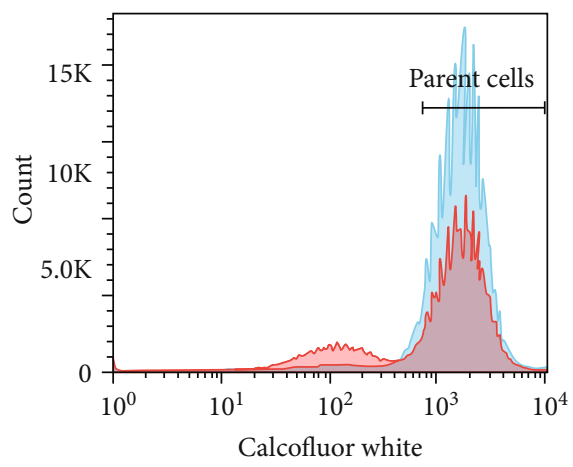

(f)

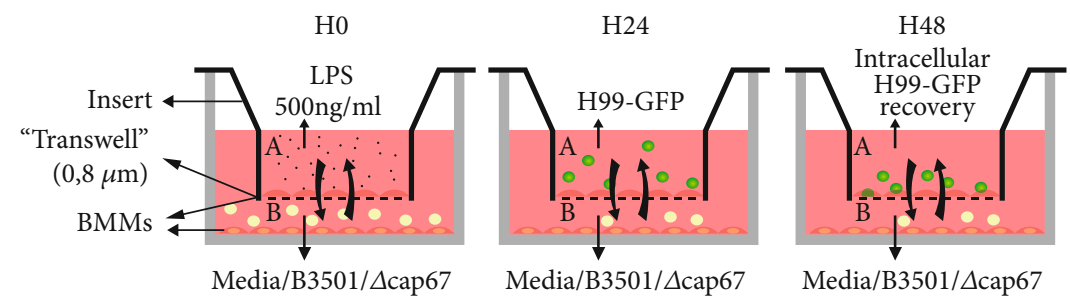

(g)

FIgure 4: Continued. 


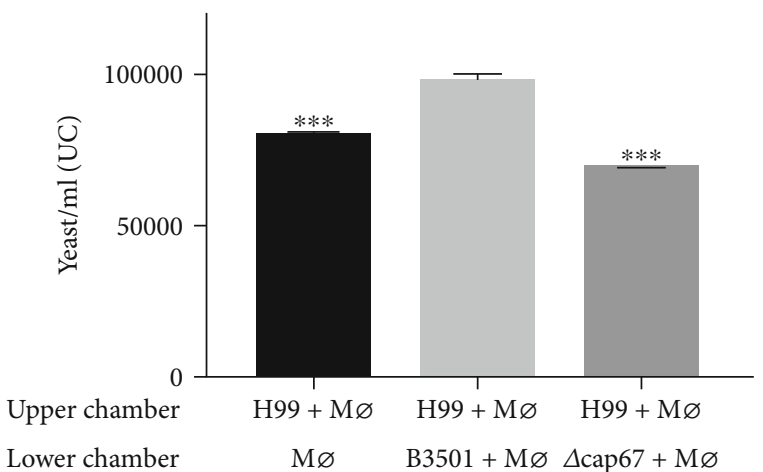

(h)

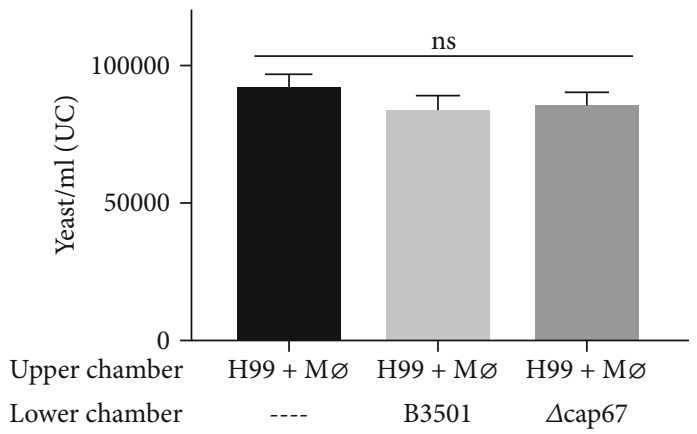

(i)

Figure 4: $1 \mathrm{kDa}$ CM35 impacts phagocytic capacity and vomocytosis events in interactions between macrophages and C. neoformans. (a) Intracellular growth (CFU of $3 \mathrm{~h}$ vs. $24 \mathrm{~h}$ postinfection) of yeasts cells in BMMs stimulated with LPS (500 ng/ml) and H99 (2:1), with or without inhibitors $(10 \% v / v)$. (b) Phagocytosis index ( $2 \mathrm{~h}$ postinfection) from BMMs stimulated with LPS (500 ng/ml) and H99 (5:1), with or without $1 \mathrm{kDa}$ CM35 $(10 \% v / v)$. (c-f) Flow cytometry analysis of (c, d) extracellular and (e, f) intracellular yeast cells (Calcofluor White high $2 \mathrm{~h}, 6 \mathrm{~h}, 12 \mathrm{~h}$, and $24 \mathrm{~h}$ postinfection) from BMMs infected with $\mathrm{H} 99(10: 1)$, with or without $1 \mathrm{kDa}$ CM35 (10\% $v / v)$. (g) Scheme for transwell infection assay, illustrating the steps taken during the assay. (h, i) Flow cytometry measurement ( $24 \mathrm{~h}$ postinfection) of intracellular yeast cells in BMMs infected with H99 $(2: 1)$, in the upper chamber of a transwell apparatus. In the lower chambers, BMMs were stimulated with LPS $(500 \mathrm{ng} / \mathrm{ml})$ and B3501 or $\Delta$ cap67 $(5: 1)(\mathrm{g})$. Alternatively, only yeast cells from B3501 or $\Delta$ cap67 in a media with LPS $(500 \mathrm{ng} / \mathrm{ml})$ were included in the lower chambers (h). Statistical analysis was performed utilizing one-way ANOVA, where ns: not significant; ${ }^{*} P \leq 0.033 ;{ }^{* *} P \leq 0.002 ;{ }^{* * *} P \leq 0.001$. Comparisons were made with the B3501 lower chamber infected group (g).

of different activators. To investigate the molecular identity of the component affecting the inflammasome, we further fractionated our media using ultrafiltration devices with nominal molecular weight cutoffs. From CM35, all these molecular weights separated inhibited IL- $1 \beta$ secretion with the exception of the fraction where the high molecular weight components were removed $(>10 \mathrm{kDa}$ ) (Figure $2(\mathrm{~d})$ ), indicating that molecules below the $1 \mathrm{kDa}$ range are responsible for inhibition of inflammasome. Since the strongest effect was achieved with the fractions below $1 \mathrm{kDa}$, the next assays were conducted utilizing this small size fraction $(<1 \mathrm{kDa} \mathrm{CM} 35)$, unless stated otherwise.

\section{3. $<1 \mathrm{kDa}$ CM35 Inhibits Caspase-1 Activation, Promoting} pro-IL-1 $\beta$ Accumulation and Cell Death Inhibition. Canonical inflammasome activation triggers various processes in the cell, including, but not limited to, IL- $1 \beta$ maturation and secretion. In that context, we analyzed other cell processes related to inflammasome activation, such as intracellular pro-IL-1 $\beta$ cleavage and cellular lysis due to caspase-1mediated pyroptosis. When macrophages were treated with $<1 \mathrm{kDa}$ CM35, $\mathrm{LDH}$ release was largely abrogated, while treatment with $<1 \mathrm{kDa}$ CMCAP or MM resulted in a smaller inhibition of macrophage cell death (Figure 3(a)), which again is likely partly explained by the presence of glycine in the media [69]. $<1 \mathrm{kDa}$ CM35 inhibited cell death (as measured by $\mathrm{LDH}$ release) following the same pattern seen for IL-1 $\beta$ secretion (Figure $3(\mathrm{a})$ ). Regarding pro-IL-1 $\beta$, the results showed that macrophages must be primed with LPS for this cytokine production and that the presence of nigericin does not alter its intracellular levels, indicating LPSdependent production of the inactive IL-1 $\beta$ (Figure 3(b)). When treated with $<1 \mathrm{kDa} C M 35$, primed macrophages exhibited an increase in intracellular pro-IL- $1 \beta$ protein, while cells treated with MM did not (Figure 3(b)). Surpris- ingly, treatment with $<1 \mathrm{kDa}$ CMCAP also induced a high accumulation of intracellular pro-IL-1 $\beta$ (Figure $3(\mathrm{~b})$ ). The pro-IL- $\beta$ production might be explained by the fact that $<1 \mathrm{kDa}$ CMCAP was the only treatment able to induce proIL-1 $\beta$ production without LPS. Both conditioned media increased $I L-1 \beta$ (i.e., pro-IL- $1 \beta$ ) transcription levels in primed macrophages, while not similarly inducing $n f \kappa b$ transcription, even after $24 \mathrm{~h}$ after LPS stimuli (S2 Fig). $<1 \mathrm{kDa}$ CMCAP alone was also able to induce TNF- $\alpha$ secretion by unprimed macrophages (S1F Fig), corroborating the assumption that this conditioned media can induce first signaling via $\mathrm{NF}-\kappa \mathrm{B}$ activation.

Having confirmed that $<1 \mathrm{kDa}$ CM35 inhibited various signals related to inflammasome activation, the next step was to observe inflammasome activation itself, analyzing the last step in the multiprotein complex assembly: the autocleavage of procaspase- 1 into the caspase- 1 active form via flow cytometry (Figures 3(c)-3(f)). Results showed that primed macrophages treated with $<1 \mathrm{kDa}$ CM35 decreased the caspase- 1 active form, compared to untreated cells or cells treated with MM. Moreover, this was independent of nigericin (Figures 3(c) and 3(d)) or infection with C. neoformans strains (Figures 3(e) and 3(f)). These results are consistent with the finding that $<1 \mathrm{kDa}$ CM35 inhibits IL- $\beta$ secretion, showing that $<1 \mathrm{kDa}$ CM35 can inhibit inflammasome activation induced via different stimuli (i.e., nigericin and infection with $\Delta c a p 67)$. Altogether, these results indicate that $<1 \mathrm{kDa}$ CM35 decreased inflammasome activation, including pyroptotic cell death, pro-IL- $1 \beta$ cleavage, the later stages of caspase- 1 activation, and consequently IL- $1 \beta$ secretion.

3.4. $<1 \mathrm{kDa}$ CM35 Impacts Phagocytic Capacity and Vomocytosis Events in Interactions between Macrophages and C. neoformans. Macrophages are critical for defense 


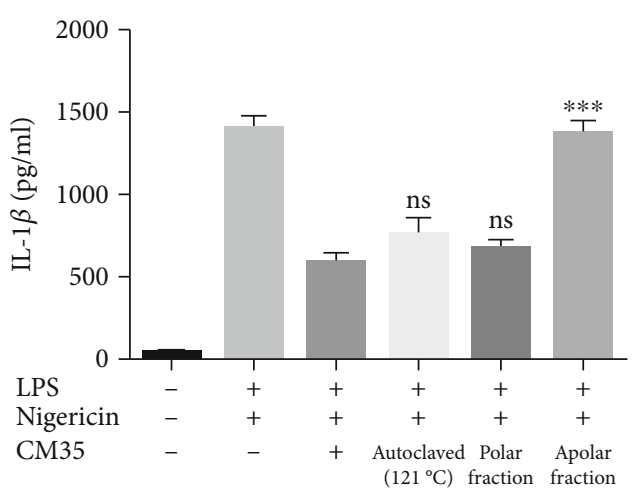

(a)

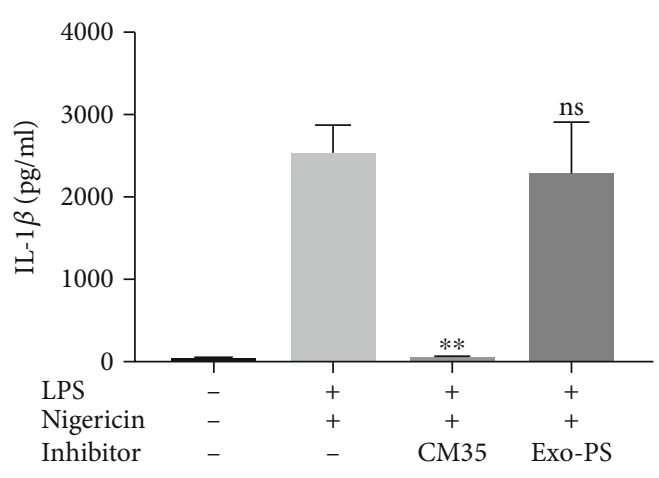

(c)

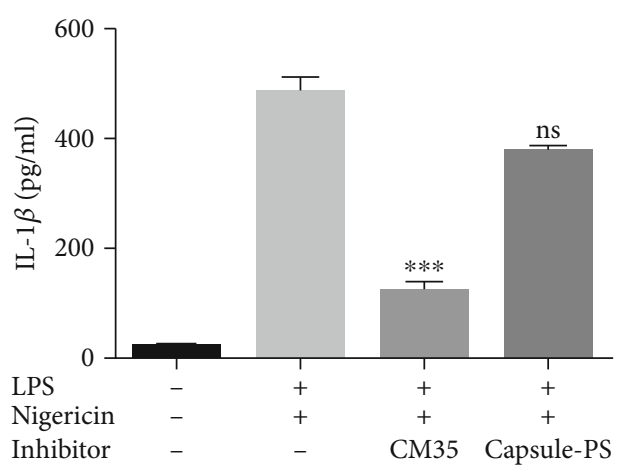

(b)

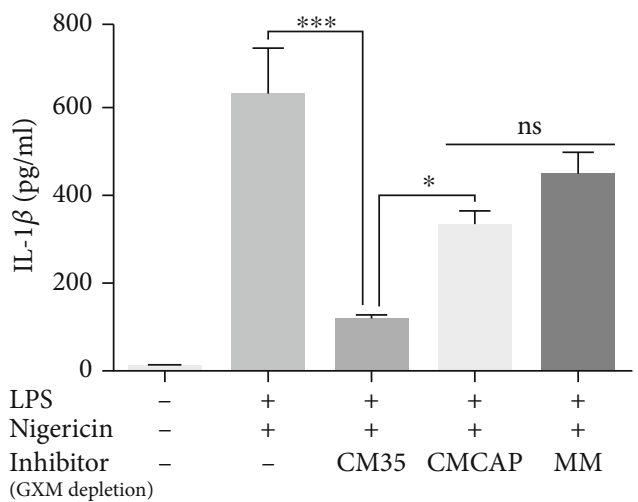

(d)

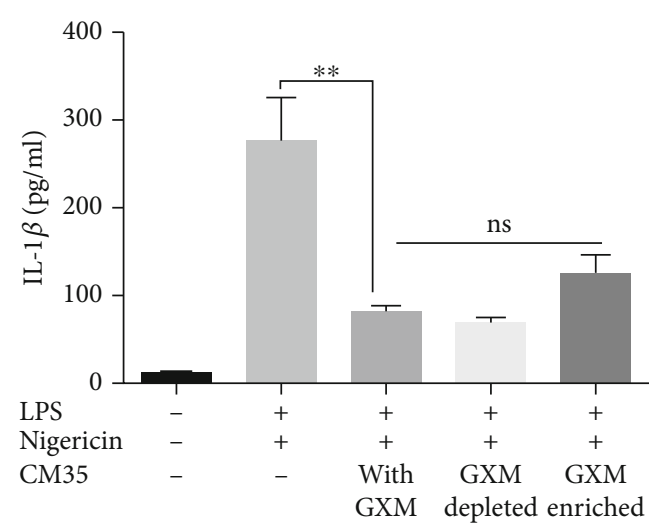

(e)

FIgURE 5: $1 \mathrm{kDa}$ CM35 inhibition characteristics indicate a small, polar molecule that does not derive from a polysaccharide origin. (a) BMMs were stimulated with LPS $(500 \mathrm{ng} / \mathrm{ml})$ and nigericin $(20 \mu \mathrm{M})$, with or without $1 \mathrm{kDa}$ CM35 fractioned by water affinity or autoclaved $(10 \% v / v$ ) overnight $(18 \mathrm{~h}) .(\mathrm{b}, \mathrm{c})$ BMMs were stimulated with LPS $(500 \mathrm{ng} / \mathrm{ml})$ and nigericin $(20 \mu \mathrm{M})$, with or without potential inhibitor $(10 \% v / v)$ overnight $(18 \mathrm{~h})$. Polysaccharides $(200 \mathrm{ug} / \mathrm{mL})$ extracted from the (c) capsule or secreted in $(\mathrm{d})$ minimal medium were used as inhibitors. (d, e) BMMs were stimulated with LPS $(500 \mathrm{ng} / \mathrm{ml})$ and/or nigericin $(20 \mu \mathrm{M})$, with or without possible inhibitor $(10 \% v / v)$ overnight $(18 \mathrm{~h})$. Conditioned medium and minimal media $(1 \mathrm{kDa}$ CM35, $1 \mathrm{kDa}$ CMCAP, and MM) were treated for GXM depletion utilizing capture ELISA and used as inhibitors $(10 \% v / v)(\mathrm{e})$. GXM recovered from ELISA was mixed with $1 \mathrm{kDa}$ CM35 and utilized as an inhibitor $(10 \% v /$ $v$ ) (f). Supernatants were recovered after stimuli and IL- $1 \beta$ secretion was quantified using ELISA. Statistical analysis was performed by one-way ANOVA, where ns: not significant; ${ }^{*} P \leq 0.033$; ${ }^{* *} P \leq 0.002$; ${ }^{* * *} P \leq 0.001$. Comparisons were made with the (a) $1 \mathrm{kDa} C M 35$ treated group or the $(b, c)$ positive control group (LPS+nigericin).

against cryptococcosis [70]. We analyzed if $>1 \mathrm{kDa}$ CM35 treatment caused a functional impairment of macrophages when infected with C. neoformans strain H99. We initially evaluated intracellular fungal burdens in macrophages when yeast cells were added simultaneously with $<1 \mathrm{kDa}$ CM35 or minimal media. Interestingly, none of the treat- ments impacted fungal intracellular growth in primed macrophages (Figure 4(a)). However, when macrophages were primed for $18 \mathrm{~h}$ with the conditioned medium, $<1 \mathrm{kDa}$ CM35 before infection, we observed a significant reduction in the phagocytic capacity of macrophages (Figure 4(b)). 


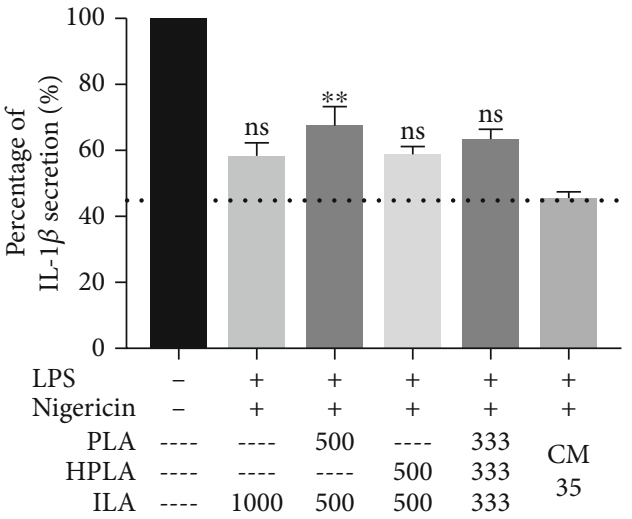

(a)

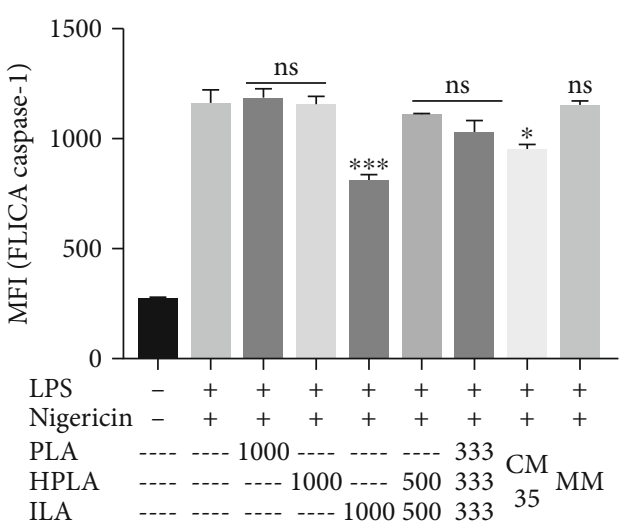

(b)

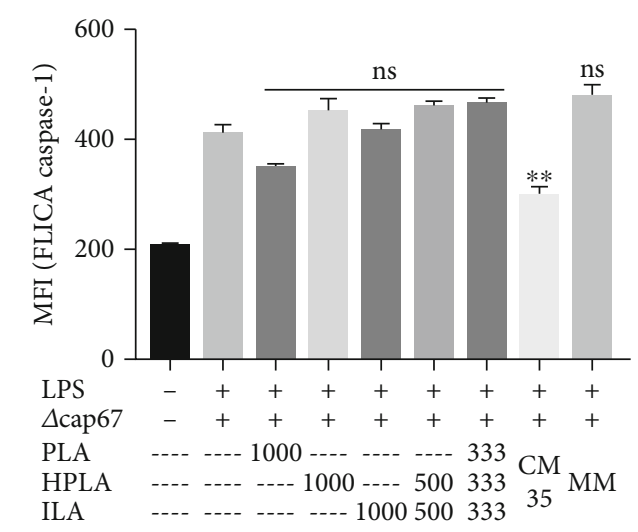

(c)

Figure 6: ILA is partly responsible for the inhibitory activity of $1 \mathrm{kDa}$ CM35. (a, b) Percentage of cytokine secretion, measured by IL-1 $\beta$ (a) release by BMMs stimulated with LPS+nigericin and the addition of possible inflammasome inhibitors (CM35, PLA, HPLA, and ILA). Positive group LPS+nigericin was normalized for a 100\% cytokine secretion. The numbers below the bars represent the concentration of the respective metabolite in $\mu \mathrm{M}$, except for $1 \mathrm{kDa}$ CM35 and MM $(10 \% v / v)$. The graph shows the metabolites alone, followed by double combinations and a triple combination of all metabolites. The bars represent three independent assays. (b, c) BMMs stimulated with LPS $(500 \mathrm{ng} / \mathrm{ml})$ and nigericin $(20 \mu \mathrm{M})$ or $\Delta$ cap67 (MOI 5:1), with or without inhibitors, were analyzed for caspase-1 activation (FLICA). $1 \mathrm{kDa}$ CM35 = conditioned media from C. neoformans B3501; MM= minimal media; PLA=DL-3-Phenyllactic acid; HPLA = DL-pHydroxyphenyllactic acid; ILA = DL-Indole-3-lactic acid. Statistical analysis was made utilizing one-way ANOVA, where ns: not significant; ${ }^{*} P \leq 0.033 ;{ }^{* *} P \leq 0.002 ;{ }^{* *} P \leq 0.001$. Comparisons were made with $1 \mathrm{kDa} C \mathrm{CM} 35$ group. ns means that the inhibition level achieved by the metabolites is similar to the inhibition achieved by $1 \mathrm{kDa}$ CM35 $(\mathrm{a}, \mathrm{b})$. Comparisons were made with the positive control (LPS+nigericin or LPS+ $\Delta$ cap67) $(c, d)$.

Another important aspect of macrophage-Cryptococcus interaction is vomocytosis. We analyzed vomocytosis in the presence of $1 \mathrm{kDa}$ CM35. Macrophages were concomitantly exposed to $<1 \mathrm{kDa}$ CM35, infected with $\mathrm{H} 99$ strain and treated with fluconazole, an antifungal drug used for extracellular growth control [29, 71]. We stained H99 cells with Uvitex and allowed macrophages to ingest. If vomocytosis occurs then that would originate highly fluorescent cells in the extracellular space as demonstrated previously. Yeast cells with lower fluorescence were considered to be derived from extracellular growth (daughter cells). We observed that macrophages treated with $1 \mathrm{kDa}$ CM35 had a higher percentage of extracellular parent cells compared to untreated macrophages (Figures $4(\mathrm{c})$ and $4(\mathrm{~d})$ ). The difference between groups starts to increase at $12 \mathrm{~h}$ of infection $(P>0.001)$, increasing once again after $24 \mathrm{~h}$ while simultaneously intracellular parent yeast cells number showed an inverse pattern, reducing after $12 \mathrm{~h}$ of infection in the groups treated with $<1 \mathrm{kDa}$ CM35 (Figures 4(e) and 4(f)). Knowing that macrophages treated with $1 \mathrm{kDa}$ CM35 present an equal rate of cell death when compared to untreated cells (Figure 3(a)), the increase of extracellular cells observed in this assay likely indicates an increase in vomocytosis rate in the presence of $<1 \mathrm{kDa}$ CM35.

To further study the impact of secreted molecules by $C$. neoformans strains, in macrophage function, a transwell assay involving two sequential infections in different chambers physically separated was carried out (Figure 4(g)). After $24 \mathrm{~h}$, all yeast cells recovered from the upper chamber exhibited high GFP fluorescence, indicating no crossing from yeast cells present in the lower chamber. H99 cells expressing GFP were used for the infection of the macrophages in the upper chamber, while nonfluorescent B3501 or $\Delta$ cap67 was used for infection in the lower chamber. A 


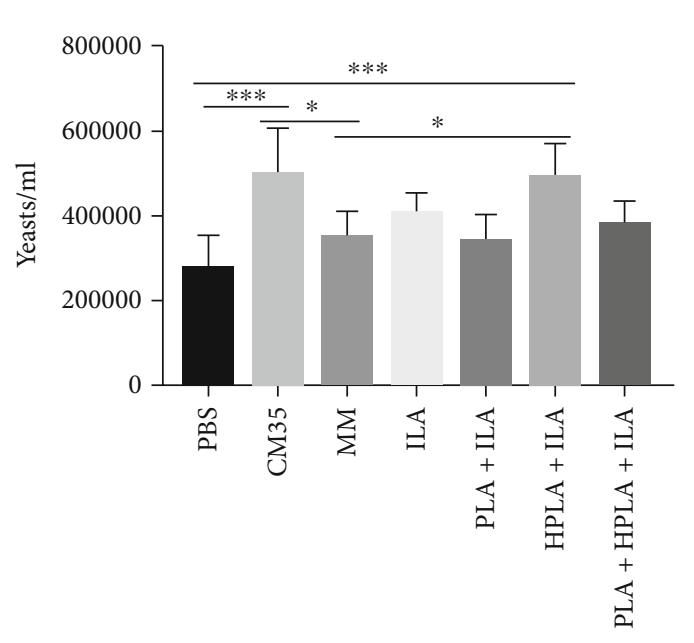

(a)

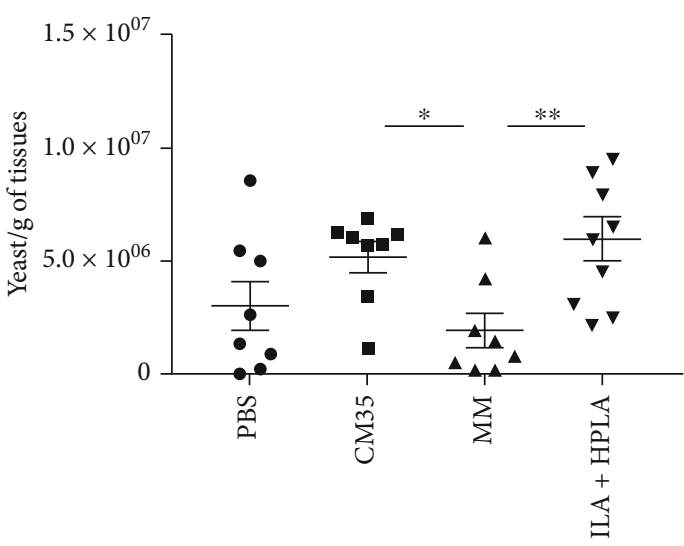

(c)

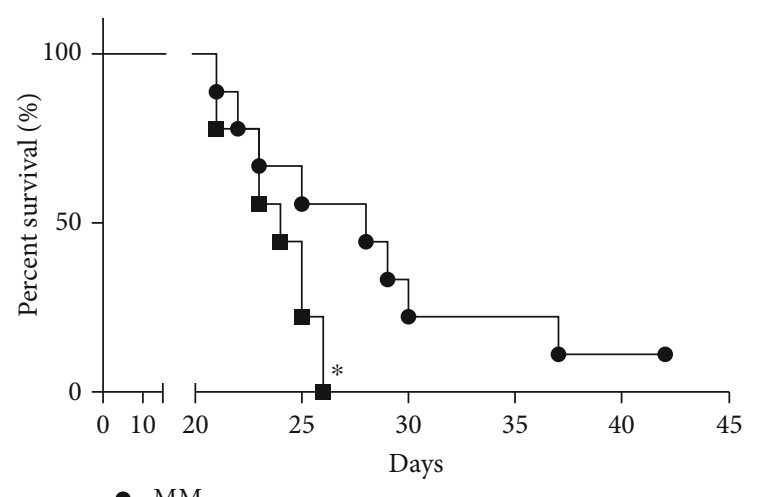

$\rightarrow \mathrm{MM}$

CM35

(b)

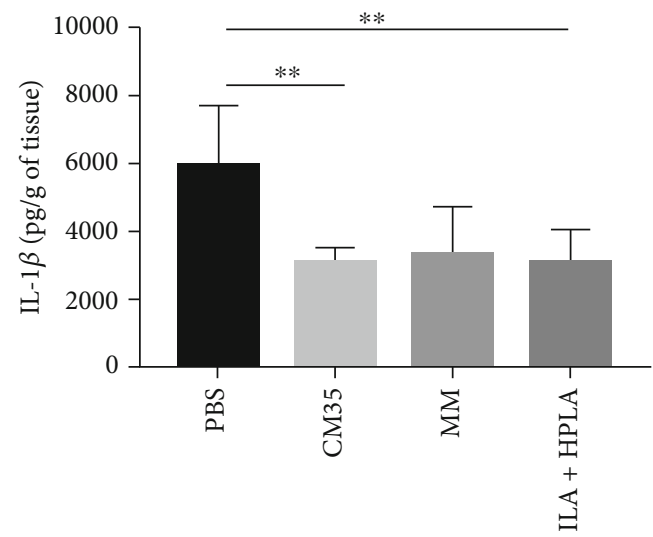

(d)

FIgURE 7: ILA and HPLA increased fungal survival in Acanthamoeba castellanii and mice experimentally infected. Intracellular growth (CFU of $3 \mathrm{~h}$ vs. $24 \mathrm{~h}$ postinfection) inside $A$. castellanii was measured by CFU after treatment with $1 \mathrm{kDa}$ CM35, MM, and ILA associated or not with PLA and HPLA. (b) The survival curve of C57Bl/6 infected with $1 \times 10^{4} \mathrm{H} 99$ strain treated with $1 \mathrm{kDa}$ CM35 or MM during each 5 days intranasally. (c) The lung fungal burden from C57Bl/e infected with $1 \times 10^{4} \mathrm{H} 99$ strain treated with $1 \mathrm{kDa}$ CM35, MM, or ILA+HPLA each 5 days intranasal repeated after 15 days postinfection. (d) IL-1 $\beta$ release in lung tissue after 15 days postinfection from $\mathrm{C} 57 \mathrm{Bl} / \mathrm{e}$ infected with $1 \times 10^{4} \mathrm{H} 99$ strain treated with $1 \mathrm{kDa}$ CM35, MM, or ILA+HPLA each 5 days intranasal repeated. $1 \mathrm{kDa}$ CM35 = conditioned media from C. neoformans B3501; $\mathrm{MM}=$ minimal media; PLA=DL-3-Phenyllactic acid; HPLA=DL-pHydroxyphenyllactic acid; ILA = DL-Indole-3-lactic acid. Statistical analysis was made utilizing one-way ANOVA, where ns: not significant; ${ }^{*} P \leq 0.033 ;{ }^{* *} P \leq 0.002 ;{ }^{* *} P \leq 0.001$. Comparisons were made with the PBS group $(\mathrm{a}, \mathrm{b})$. Comparisons were made with the (c) MM or (d) PBS group.

significantly higher intracellular fungal burden was observed in macrophages infected with $\mathrm{H} 99$ strain in a chamber vertically adjacent to the bottom chamber containing macrophages infected with B3501 strain compared to fungal burden when the adjacent chamber contained macrophages alone or macrophages infected with $\Delta c a p 67$ strain or uninfected macrophages (Figure 4(h)). Interestingly, the increase in fungal burden derived by B3501 was not observed when only yeast cells were seeded in the bottom chambers, i.e., the factor produced by B3501 strain is only produced in a stressed milieu, as in the presence of macrophages (Figure 4(i)).

Overall, these experiments indicate that $<1 \mathrm{kDa}$ CM35 secreted by B3501 alters macrophage function such that macrophage antifungal activity is affected, potentially by secreting molecules that inhibit a proinflammatory environment.
3.5. $<1 \mathrm{kDa}$ CM35 Inhibition Characteristics Indicate That a Small, Polar, and Nonpolysaccharide Molecule Is Responsible for the Effects. To further characterize the conditioned medium, $<1 \mathrm{kDa}$ CM35 was submitted to autoclaving and separated into polar and nonpolar soluble fractions. Autoclaved and polar fraction of CM35 retained its inhibitory properties (Figure 5(a)). Crude $<1 \mathrm{kDa}$ CM35 was also treated with various proteases before its addition to primed macrophages. None of the treatments eliminated the inhibition promoted by the conditioned media, and the proteases themselves also did not significantly alter IL- $1 \beta$ secretion (data not shown). Overall, the analysis showed that a small, polar, and heat and protease-resistant molecule (or molecules) resulted in the $<1 \mathrm{kDa}$ CM35 inhibitory properties.

GXM is a known virulence factor that matches the characteristics possessed by our candidate molecule. While 
generally depicted as a high molecular weight polysaccharide, this polymer can also exist as lower molecular weight species [72]. We decided to investigate the role of GXM and GXMderived molecules when interacting with activated macrophages and in the context of $<1 \mathrm{kDa}$ CM35 treatment, i.e., if we could detect these molecules in macrophages treated with CM35 below $1 \mathrm{kDa}$ size fraction, but not if treated with $<1 \mathrm{kDa}$ CMCAP (S3 Fig). Firstly, polysaccharides derived from the yeast capsule (Figure 5(b)) or exopolysaccharides obtained from the culture media (Figure 5(c)) were used to treat macrophages primed with LPS and nigericin. None of these treatments were able to significantly reduce IL- $1 \beta$ secretion compared to $<1 \mathrm{kDa} C M 35$, suggesting that GXM is not enough to promote inflammasome inhibition.

Similarly, depleting GXM from $<1 \mathrm{kDa}$ CM35 using mAb $18 \mathrm{~B} 7$ capture protocol [59] did not alter IL- $1 \beta$ secretion by activated macrophages (Figure 5(d)). Supporting the hypothesis that GXM is not the candidate molecule, the recovery of GXM from the coated ELISA plate and enrichment of its content in the $<1 \mathrm{kDa}$ CM35 did not significantly affect IL$1 \beta$ secretion (Figure 5(e)). Although GXM may be isolated together with our candidate molecule, these assays indicate that GXM does not affect inflammasome inhibition seen in our model.

\subsection{DL-p-Hydroxyphenyllactic Acid (HPLA) and DL-Indole-} 3-Lactic Acid (ILA) Participate in Inflammasome Inhibition Property Possessed by $<1 \mathrm{kDa}$ CM35. Given that GXM did not interfere in our inflammasome activation model, we pursued the identification of our active candidate molecule by analyzing $<1 \mathrm{kDa}$ CM35 and $<1 \mathrm{kDa}$ CMCAP using mass spectrometry. Three candidates met our criteria of being enriched in CM35 vs. CMCAP, small, polar, and heat and protease-resistant molecules: DL-3-Phenyllactic acid (PLA), DL-p-Hydroxyphenyllactic acid (HPLA), and DL-Indole-3lactic acid (ILA) (S4 Fig). All three are aromatic metabolites derived from amino acid metabolism and are produced by several species of prokaryotes and eukaryotes [73, 74]. Testing these three metabolites separately revealed that ILA, alone or with HPLA, mimicked the activity of $>1 \mathrm{kDa}$ CM35 (Figure 6(a)), and ILA alone or associated with HPLA inhibited IL1 $\beta$ secretion and did not affect TNF- $\alpha$ secretion (Figure 6(a)). Notably, ILA alone reduced caspase-1 activation to levels similar to that achieved with $<1 \mathrm{kDa}$ CM35 (Figure 6(b)). Interestingly, ILA did not reduce caspase-1 activation when macrophages were activated with $\Delta$ cap67 infection instead of nigericin (Figure $6(\mathrm{c})$ ). This result suggests that ILA may participate in $<1 \mathrm{kDa}$ CM35 inhibition properties, but that it is not the single molecule responsible for this capacity. Hence, it is possible that $<1 \mathrm{kDa}$ CM35 inhibitory properties are due to a combination of molecules. At this point, we identify ILA and HPLA as immunomodulatory metabolites produced by $C$. neoformans.

3.7. Conditioned Media Also Promotes Survival of $C$. neoformans in Acanthamoeba castellanii and Mouse Infection. To evaluate the properties of $<1 \mathrm{kDa}$ CM35 in promoting $C$. neoformans survival during infection in other organisms, A. castellanii were infected with H99 strain of $C$. neoformans and treated or not with $<1 \mathrm{kDa}$ CM35 or aromatic metabolites. The quantification of CFU was performed $24 \mathrm{~h}$ postinfection and showed a significantly higher fungal load inside amoebas in the groups treated with $<1 \mathrm{kDa}$ CM35 and ILA combined with HPLA, compared to the other groups (Figure $7(\mathrm{a})$ ), indicating that both ILA+HPLA and $<1 \mathrm{kDa}$ CM35 enhance fungal survival inside $A$. castellanii. To evaluate if $<1 \mathrm{kDa}$ CM35 was effectively favoring $C$. neoformans survival and increasing infection in a more complex host, we treated or not infected mice with $<1 \mathrm{kDa}$ CM35 or MM, each 5 days, and analyzed their survival for 45 days (Figure 7(b)). Mice treated with MM survived longer than mice treated with $<1 \mathrm{kDa} C M 35$, showing that active metabolites in $<1 \mathrm{kDa}$ CM35 enhance infection. Furthermore, when infected $\mathrm{C} 57 \mathrm{BL} / 6$ mice were treated with $<1 \mathrm{kDa}$ CM35 or ILA plus HPLA at two and seven days postinfection, the fungal load was significantly higher in the lungs of mice treated with $<1 \mathrm{kDa}$ CM35 or ILA+HPLA (Figure 7(c)) compared to the lungs of mice treated with PBS or MM at 14 days of infection. Contributing to this result, we found significantly lower levels of IL-1 $\beta$ in the lungs of mice treated with $<1 \mathrm{kDa}$ CM35 or ILA+HPLA, but not with MM (Figure 7(d)).

\section{Discussion}

The processes by which fungi manipulate the mammalian immune systems and in particular their interaction with inflammasome pathways remain unknown. Although the significant receptors involved and most of the stress signals required for inflammasome activation are known, the mechanisms by which fungal pathogens modulate and/or evade these responses are still poorly understood, when compared to its bacterial counterparts. Here, we demonstrate that molecules secreted by $C$. neoformans can specifically inhibit the canonical activation of the inflammasome pathway and dampen macrophage anticryptococcal activity and mouse immune response, potentiating fungal survival and growth during the host-pathogen interaction. Furthermore, we determined that GXM did not participate in this process, and we identified one molecule partially responsible for the effect promoted by the fungal conditioned media.

Inflammasome activation is associated with a proinflammatory response, mainly due to its IL- $1 \beta$ and IL- 18 processing properties. Both are critical cytokines for macrophage activation as well as in the development of Th17 and Th1 polarization, respectively [44]. Therefore, inflammasome activation critically affects Th1/Th17 polarization which is widely reported as a protective response against pathogenic fungi. NLRP3 defects are therefore associated with a poor prognosis upon fungal infection, ranging from severe susceptibility in invasive candidiasis [46] to milder susceptibility to cryptococcosis [52]. On the other hand, NLRP3 defects have also been associated with a better prognosis in aspergillosis associated with cystic fibrosis [75], and these defects had no impact in chromoblastomycosis [50]. Hence, inflammasome activation has different effects depending on the fungal pathogen and the associated pathologies of the host. 
As the canonical inflammasome scaffold involves various proteins and downstream signaling, numerous steps can be inhibited to prevent scaffold formation, thus preventing the cascade at several steps with different consequences to the cell activation. A single point of interference is sufficient to disrupt the entirety of downstream signaling and inflammasome function, from receptor activation to caspase autolysis [76]. Inflammasome activation can also be partially prevented by the use of cytoprotective agents like glycine [69]. Our study demonstrated that conditioned media from $C$. neoformans strain B3501 promoted robust inhibition of IL$1 \beta$ secretion and complete inhibition of $\mathrm{LDH}$ release, although it had less of an impact on caspase-1 activation. IL- $1 \beta$ can be secreted by various mechanisms, depending on the cell status, for example, through membrane pores formed by Gasdermin D or through cell membrane defects during pyroptosis [77]. In this model, glycine was not able to prevent pore formation in immortalized macrophages, consequently preventing LDH release but not cytokine secretion. Studies also depicted that dying macrophages undergoing pyroptosis were the primary source of IL- $1 \beta$ secretion in an in vitro model, with peritoneal macrophages exhibiting caspase- 1 activation and a cytokine burst that coincided with the moment of cell death. Interestingly, caspase- 1 activation inhibition prevented IL- $1 \beta$ secretion, but it did not alter cell death events $[78,79]$. Taken together, these findings show that both events can occur independently, even if they are mostly caspase- 1 dependent and depend on the inflammasome stimuli, cell type, and inhibition scheme utilized.

In our model, glycine and MM containing glycine dampened IL- $1 \beta$ and LDH release if nigericin was used as stimuli when interacting with the cells for an extended period before inflammasome activation, but not when inflammasome activation was promoted by $\Delta$ cap67 infection [69]. Another interesting feature presented in our inflammasome inhibition model was the accumulation of pro-IL- $1 \beta$ intracellularly in cells treated with CM35. It is well characterized that neither caspase- 1 activation nor inhibition has any impact on proIL-1 $\beta$ intracellular levels in activated cells, indicating that IL- $1 \beta$ translation is stable regardless of whether it is subsequently cleaved [80]. One explanation for this stability of intracellular levels during caspase-1 inhibition is that proIL-1 $\beta$, along with other inflammasome unrelated proteins, are present in the supernatant of necrotic cells undergoing NLRP3 activation [79]. On the other hand, changes in the intracellular cytokine reservoir can impact the secretion of its mature form [81]. In our work, an increase in pro-IL- $1 \beta$ intracellular levels occurred concomitantly with a decrease in IL- $1 \beta$ mature form release, which is not fully explained by the inhibition seen in caspase- 1 activation. One aspect of our model is that pyroptosis is prevented in the presence of CM35, suggesting that intracellular proteins are retained during NLRP3 activation in this group. Furthermore, transcripts of $I L-1 \beta$ were highly expressed in the cells treated with CM35. Regarding inflammasome inhibition and pro-IL- $1 \beta$, Folco et al. demonstrated that macrophages primed with LPS and treated with bafilomycin, a known inhibitor of the NLRP3-dependent receptor activation, exhibited increased intracellular levels of this cytokine [82].
The first studies depicting inflammasome activation by fungi demonstrated that morphogenesis is important to promote NLRP3 inflammasome activation; hence, some morphotypes of a pathogen can induce a more robust response than others $[48,83]$. C. neoformans is also known to be a weak inflammasome activator. In this context, GXM has been considered the main factor for the yeast to evade inflammasome activation, promoting the evasion of phagocytosis and prevention of recognition by extracellular receptors [52-54].

The only well-described direct modulation of the inflammasome pathway to date with a focus on fungicidal activity has been with $C$. albicans internalized hyphae in which the secretion of a candidalysin leads to cell piercing, NLRP3 inflammasome activation, and host cell death via pyroptosis [84-87]. Despite the lack of further published evidence for fungal inhibition of inflammasome activation, many other intracellular pathogens, like bacteria and viruses, have welldescribed mechanisms for NLRP3 suppression. The human pathogenic bacteria of the genus Yersinia express a conserved type III secretion system (T3SS) as a virulence trait, which is associated with inflammasome activation. This secretion system is responsible for the release of effector proteins called Yersinia outer proteins (Yops), and two Yops can inhibit inflammasome activation: YopK is related to prevention of T3SS recognition by NLR receptors [88], and YopM is related to blockage of pyrin inflammasome activation [89]. Defects in both effector proteins lead to more robust inflammasome activation and bacterial clearance, highlighting the importance of the inhibition promoted by the pathogen. Poxviruses produce proteins homologous to mammalian proteins responsible for inflammasome inhibition, known as pyrin domain-only proteins (POP) and serpins. These viral proteins bind to ASC or caspase domains, preventing proper inflammasome assembly and activity from promoting the intracellular survival of the poxvirus [90]. Therefore, it is not surprising to demonstrate that $C$. neoformans-derived molecules can specifically inhibit inflammasome activity, and it is feasible to hypothesize that other fungal-driven mechanisms for inflammasome inhibition will be discovered soon.

While most studies have shown that IL-18 is important during cryptococcosis, IL- $1 \beta$ itself is sometimes depicted as unnecessary for host protection [55]. However, a recent study has shown that IL-1R signaling is essential for a Th1/Th17 polarization in a chronic infection model, consequentially facilitating fungal clearance by the host [56]. These data corroborate the importance of the NLRP3 components during cryptococcosis [52]. We demonstrate that macrophages treated with CM35 had a reduced capacity to control C. neoformans; the secretion of inflammasome-related cytokines is usually accompanied by cell death via pyroptosis. This cellular lysis releases a high content of proinflammatory IL-1 family cytokines, therefore activating neighboring cells thus promoting the maintenance of a proinflammatory environment [78]. Overall, inflammasome activation is related to a more effective response against $C$. neoformans, eliciting polarization towards Th1 and promoting antimicrobial macrophage activation; consequently, inhibition of this pathway 
reduces the responsiveness of the macrophages against the fungus.

The mechanisms and causes of vomocytosis are still poorly understood, but it is accepted that macrophages undergo vomocytosis because they cannot control their intracellular fungal burden [77]. Therefore, macrophages release the fungus to the extracellular environment instead of permitting themselves to serve as a protected niche for cryptococcal replication. Extracellular yeasts are less capable of evading the immune killing, and therefore, vomocytosis should lead to milder disease and is considered relatively protective [91]. Alanio and colleagues demonstrated that the outcome of human patients was highly correlated with the intracellular growth rate of virulent strains of $C$. neoformans [64], supporting this vomocytosis immune evasion hypothesis. Our results indicate that macrophages treated with CM35 have a higher rate of vomocytosis events, suggesting that the inhibition in the inflammatory response and pyroptosis promoted by the conditioned media might also enhance vomocytosis as an alternative mechanism to expel fungal burden to mitigate against host cell death.

ILA is an aromatic metabolite derived from the tryptophan pathway. It is produced by a wide variety of organisms and microorganisms, ranging from soil bacteria to humans $[73,74]$. ILA production in fungi is mostly commonly seen in endophytic and phytopathogenic species and necessary for plant tissue colonization [92]. The tryptophan degradation pathway that leads to ILA production has an intermediate product denominated indolepyruvate, which is transformed in ILA as a result of a reduction-oxidation reaction by the NADPH-dependent enzyme indole-3-lactate dehydrogenase. Although this pathway and responsible enzymes have not yet been fully annotated in C. neoformans or C. albicans, the presence of ILA has been observed in conditioned media from both pathogenic yeasts [93]. Zelante et al. correlated the production of tryptophan catabolites by mouse gut microbiota, among then ILA, with mucosal protection from inflammation and resistance in a candidiasis infection model, which is mediated via IL-22 production [94].

In recent years, various enzymes and proteins related to biosynthesis metabolic pathways have been depicted as important for pathogenesis in cryptococcosis infection models, especially those associated with glucose metabolism. Defects in pyruvate and hexose kinases and in acetyl-CoA production impact virulence traits of the yeast, resulting in a reduction in host mortality $[95,96]$. Nevertheless, our knowledge regarding aromatic metabolites derived from amino acid metabolism secreted by $C$. neoformans and their impact on the host during infection is severely limited. Notably, amino acid permeases are essential for the protection of the yeast when challenged by environmental or hostpromoted stress conditions. C. neoformans mutants with a defect in these enzymes are less virulence, highlighting the importance of amino acid uptake during infection [97]. Yeast cells deficient in a small protein allegedly involved in the citric acid cycle had a higher expression of amino acids (i.e., tryptophan), and the mutant cells were more lethal in mice compared to wild-type yeast cells [98]. Another interesting aspect of this study was the demonstration that the intracellular fungal burden in macrophages infected with the mutant was only higher in the presence of exogenous NADPH, a cofactor that is essential to produce ILA from indol-3pyruvate [86].

Although there is no report correlating aromatic metabolites and inflammasome inhibition, some small molecules with structures similar to aromatic metabolites are known to inhibit inflammasome. Glyburide is one of the most well-described inhibitors for NLRP3 activation, acting on ATP-sensitive potassium channels to block potassium efflux, which prevents inflammasome activation. Glyburide is a sulfonylurea drug with aromatic hydrocarbons in its structure [99]. Interestingly, not all sulfonylurea drugs are able to prevent IL- $1 \beta$ secretion via inflammasome inhibition, and there are reports of sulfonylurea drugs that prevent inflammasome activation by mechanisms other than potassium efflux blockage [100] which we hypothesize may be similar to the effects of ILA.

\section{Conclusions}

This work identifies new effects mediated by C. neoformans wild-type secreted molecules, especially in the ability to modify the activation of the intracellular inflammasome pathway. Treating macrophages with conditioned media reduced such critical functions such as phagocytosis and intracellular killing in in vitro infection models, suggesting a possible new mechanism for fungal persistence inside the host. We also found that the aromatic metabolite ILA mimics the inhibitory properties of CM35. Future studies regarding ILA and CM35 effects in fungal infection are essential to determine the detailed mechanism of action, to define where along the signaling pathway that the inflammasome is being affected and identifying other molecules that participate in inflammasome inhibition. An in-depth analysis of how these molecules impact cryptococcal infection would significantly enhance our understanding of cryptococcosis and perhaps lead to new strategies to prevent and treat $C$. neoformans disease.

\section{Abbreviations}

ASC: $\quad$ Apoptosis-associated speck-like protein containing a CARD

BMDC: Bone marrow-derived dendritic cells with GMCSF stimulus

BMDM: Bone marrow-derived macrophages with GMCSF stimulus

BMM: $\quad$ Bone marrow-derived macrophages with M-CSF stimulus

CFU: $\quad$ Colony forming units

CM35: Conditioned media obtained from B3501 culture

CMCAP: Conditioned media obtained from $\Delta$ cap67 culture

ELISA: Enzyme-linked immunosorbent assay

GM-CSF: Granulocyte-macrophage colony-stimulating factor

GXM: Glucuronoxylomannan

HPLA: DL-p-Hydroxyphenyllactic acid

IL-18: Interleukin 18 


$\begin{array}{ll}\text { IL-1 } \beta: & \text { Interleukin } 1 \text { beta } \\ \text { ILA: } & \text { DL-Indole-3-lactic acid } \\ \text { kDa: } & \text { Kilodalton } \\ \text { LDH: } & \text { Lactate dehydrogenase } \\ \text { LPS: } & \text { Lipopolysaccharide } \\ \text { mAb: } & \text { Monoclonal antibody } \\ \text { M-CSF: } & \text { Macrophage colony-stimulating factor } \\ \text { MM: } & \text { Minimal media } \\ \text { NLRP3: } & \text { NLR pyrin domain-containing } 3 \\ \text { PBS: } & \text { Phosphate-buffered saline } \\ \text { PLA: } & \text { 3-Phenyllactic acid } \\ \text { PS: } & \text { Polysaccharide } \\ \text { TNF- } \alpha: & \text { Tumor necrosis factor alpha. }\end{array}$

\section{Data Availability}

The data used to support the findings of this study are available from the corresponding author upon request.

\section{Conflicts of Interest}

The authors declare that there is no conflict of interest regarding the publication of this paper.

\section{Authors' Contributions}

A.H.T. and A.L.B. share senior authorship of this article.

\section{Acknowledgments}

We thank Guilaume E. Desanti (University of Birmingham) for technical assistance. We thank Julie M. Wolf (Albert Einstein College of Medicine) for providing capsule polysaccharides. We thank Dario Zamboni (University of São Paulo) and Kelly Magalhães (University of Brasília) for initial discussions. This study was financially supported by the Conselho Nacional de Desenvolvimento Científico e Tecnológico (CNPq) (470059/2014-1) and the Coordenação de Aperfeiçoamento de Pessoal de Nível Superior (CAPES) (005/2012). "RCM is supported by the European Research Council under the European Union's Seventh Framework Programme (FP/2007-2013)/ERC Grant Agreement No. 614562 Wolfson Royal Society Research Merit Award.”

\section{Supplementary Materials}

S1 Fig: CM35, but not CMCAP or minimal media, is able to reduce IL- $1 \beta$ secretion. Secretion of IL- $1 \beta$ was measured from BMDMs stimulated with LPS (500 $\mathrm{ng} / \mathrm{ml})$ and nigericin $(20 \mu \mathrm{M})$, with or without possible inhibitor $(10 \% v / v)$ overnight (18h) (A). Secretion of TNF- $\alpha$ was measured from BMDMs (B), BMMs (C), and DCs (D) stimulated with LPS $(500 \mathrm{ng} / \mathrm{ml})$ and nigericin $(20 \mu \mathrm{M})$, with or without possible inhibitor $(10 \% v / v)$ overnight $(18 \mathrm{~h})$. Alternatively, BMDMs were treated with possible inhibitors overnight $(18 \mathrm{~h})$ previously to stimulation with LPS $(500 \mathrm{ng} / \mathrm{ml})$ for $4 \mathrm{~h}(\mathrm{E})$. TNF$\alpha$ release measured from supernatants of BMMs stimulated with nigericin $(20 \mu \mathrm{M})$, with or without CMCAP (F). Secretion of IL- $1 \beta(\mathrm{G})$ or TNF- $\alpha(\mathrm{H})$ was measured from BMMs stimulated with LPS $(500 \mathrm{ng} / \mathrm{ml})$ and nigericin $(20 \mu \mathrm{M})$, with or without possible inhibitor $(10 \% v / v)$ overnight $(18 \mathrm{~h})$. Supernatants were collected after stimulus and cytokines measured by ELISA technique. CM35 = conditioned media from B3501; CMCAP = conditioned media from $\Delta c a p 67$; $\mathrm{MM}=$ minimal media; $\mathrm{CM} 99=$ conditioned media from H99. Statistical analysis was performed utilizing one-way ANOVA, where ns: not significant; ${ }^{*} P \leq 0.033 ;{ }^{* * *} P \leq 0.001$ . S2 Fig: CMs induce IL- $1 \beta$ transcription in activated macrophages. Transcript levels of IL- $1 \beta$ (A) and Nf- $\kappa \mathrm{B}(\mathrm{B})$ from cDNA extracted from BMMs stimulated with LPS $(500 \mathrm{ng} / \mathrm{ml})$ and/or nigericin $(20 \mu \mathrm{M})$, with or without potential inhibitor $(10 \% v / v)$ overnight $(18 \mathrm{~h})$. IL- $1 \beta$ or Nf- $\kappa \mathrm{B}$ to GAPDH relative expression was calculated using the $2^{(-\mathrm{ct})}$ method and normalized to the level of unstimulated BMMs. Statistical analysis was achieved by one-way ANOVA, where ns: not significant; ${ }^{*} P \leq 0.033 ;{ }^{* * *} P \leq 0.001$. Comparisons were made with the LPS+nigericin group. S3 Fig: GXM detection in $\mathrm{CM}$ samples. (A-C) BMMs interacting with inhibitors CM35 (A), CM35<1 kDa (B), and CMCAP (C). (D-F) BMMs interacting with CM35 inhibitor before GXM depletion treatment by capture ELISA (D), after treatment (E) and enriched with GXM eluted from the ELISA plate (F). Cells were stained for the nucleus (blue) and GXM (red). Images were taken in a confocal fluorescence microscope. S4 Fig: mass spectrometry comparative CM analysis. (A) Heat map based on extracted metabolite significant intensities from CM35 and CMCAP. (B-D) Comparative data from each aromatic metabolite detected in the analysis. (Supplementary Materials)

\section{References}

[1] B. J. Park, K. A. Wannemuehler, B. J. Marston, N. Govender, P. G. Pappas, and T. M. Chiller, "Estimation of the current global burden of cryptococcal meningitis among persons living with HIV/AIDS," AIDS, vol. 23, no. 4, pp. 525530, 2009.

[2] R. Rajasingham, R. M. Smith, B. J. Park et al., "Global burden of disease of HIV-associated cryptococcal meningitis: an updated analysis," The Lancet Infectious Diseases, vol. 17, no. 8, pp. 873-881, 2017.

[3] M. S. Lazera, M. A. S. Cavalcanti, A. T. Londero, L. Trilles, M. M. Nishikawa, and B. Wanke, "Possible primary ecological niche of Cryptococcus neoformans," Medical Mycology, vol. 38, no. 5, pp. 379-383, 2000.

[4] D. T. Takahara, M. d. S. Lazera, B. Wanke et al., "First report on Cryptococcus neoformans in pigeon excreta from public and residential locations in the metropolitan area of Cuiabá, state of Mato Grosso, Brazil," Revista do Instituto de Medicina Tropical de São Paulo, vol. 55, no. 6, pp. 371376, 2013.

[5] X. Lin and J. Heitman, "The biology of the Cryptococcus neoformans species complex," Annual Review of Microbiology, vol. 60, no. 1, pp. 69-105, 2006.

[6] X. Lin, "Cryptococcus neoformans: morphogenesis, infection, and evolution," Infection, Genetics and Evolution, vol. 9, no. 4, pp. 401-416, 2009.

[7] T. Sorrell and D. Ellis, "Ecology of Cryptococcus neoformans," Revista Iberoamericana de Micología, vol. 14, no. 2, pp. 42-43, 1997. 
[8] A. Idnurm, Y.-S. Bahn, K. Nielsen, X. Lin, J. A. Fraser, and J. Heitman, "Deciphering the model pathogenic fungus Cryptococcus neoformans," Nature Reviews. Microbiology, vol. 3, no. 10, pp. 753-764, 2005.

[9] T. Mitchell and J. Perfect, "Cryptococcosis in the era of AIDS100 years after the discovery of Cryptococcus neoformans," Clinical Microbiology Reviews, vol. 8, no. 4, pp. 515-548, 1995.

[10] F. Almeida, J. M. Wolf, and A. Casadevall, "Virulence-associated enzymes of Cryptococcus neoformans," Eukaryotic Cell, vol. 14, no. 12, pp. 1173-1185, 2016.

[11] L. M. Taylor-Smith and R. C. May, "New weapons in the Cryptococcus infection toolkit," Current Opinion in Microbiology, vol. 34, pp. 67-74, 2016.

[12] M. L. Rodrigues, E. S. Nakayasu, D. L. Oliveira et al., "Extracellular vesicles produced by Cryptococcus neoformans contain protein components associated with virulence," Eukaryotic Cell, vol. 7, no. 1, pp. 58-67, 2008.

[13] D. L. Oliveira, C. G. Freire-de-Lima, J. D. Nosanchuk, A. Casadevall, M. L. Rodrigues, and L. Nimrichter, "Extracellular vesicles from Cryptococcus neoformans modulate macrophage functions," Infection and Immunity, vol. 78, no. 4, pp. 1601-1609, 2010.

[14] P. R. Williamson, "Laccase and melanin in the pathogenesis of Cryptococcus neoformans," Frontiers in Bioscience, vol. 2, no. 5, pp. e99-107, 1997.

[15] J. W. Kronstad, R. Attarian, B. Cadieux et al., "Expanding fungal pathogenesis: Cryptococcus breaks out of the opportunistic box," Nature Reviews. Microbiology, vol. 9, no. 3, pp. 193-203, 2011.

[16] T. R. O'Meara and J. Alspaugh, "The Cryptococcus neoformans capsule: a sword and a shield," Clinical Microbiology Reviews, vol. 25, no. 3, pp. 387-408, 2012.

[17] S. Frases, B. Pontes, L. Nimrichter, M. L. Rodrigues, N. B. Viana, and A. Casadevall, "The elastic properties of the Cryptococcus neoformans capsule," Biophysical Journal, vol. 97, no. 4, pp. 937-945, 2009.

[18] O. Zaragoza, M. L. Rodrigues, M. De Jesus, S. Frases, E. Dadachova, and A. Casadevall, The capsule of the fungal pathogen Cryptococcus neoformans, vol. 68Elsevier Inc, 1st edition, 2009.

[19] T. Kozel and E. Gotschlich, "The capsule of Cryptococcus neoformans passively inhibits phagocytosis of the yeast by macrophages," The Journal of Immunology, vol. 129, pp. 16751680, 1982.

[20] S. M. Levitz and D. J. DiBenedetto, "Paradoxical role of capsule in murine bronchoalveolar macrophage-mediated killing of Cryptococcus neoformans," The Journal of Immunology, vol. 142, no. 2, pp. 659-665, 1989.

[21] A. Vecchiarelli, D. Pietrella, P. Lupo, F. Bistoni, D. C. Mcfadden, and A. Casadevall, "The polysaccharide capsule of Cryptococcus neoformans interferes with human dendritic cell maturation and activation sular strains of Cryptococcus neoformans to acti- differentiation, as documented by the enhance- maturation, indicating a new pathway by," Journal of Leukocyte Biology, vol. 74, no. 3, pp. 370-378, 2003.

[22] C. Monari, E. Pericolini, G. Bistoni, A. Casadevall, T. R. Kozel, and A. Vecchiarelli, "Cryptococcus neoformansCapsular glucuronoxylomannan induces expression of Fas ligand in macrophages," Journal of Immunology, vol. 174, no. 6, pp. 3461-3468, 2005.
[23] C. Monari, F. Bistoni, A. Casadevall et al., "Glucuronoxylomannan, a microbial compound, regulates expression of costimulatory molecules and production of cytokines in macrophages," The Journal of Infectious Diseases, vol. 191, no. 1, pp. 127-137, 2005.

[24] C. Monari, F. Bistoni, and A. Vecchiarelli, "Glucuronoxylomannan exhibits potent immunosuppressive properties," FEMS Yeast Research, vol. 6, no. 4, pp. 537-542, 2006.

[25] A. Vecchiarelli, C. Retini, D. Pietrella et al., "Downregulation by cryptococcal polysaccharide of tumor necrosis factor alpha and interleukin-1 beta secretion from human monocytes," Infection and Immunity, vol. 63, pp. 2919-2923, 1995.

[26] A. Vecchiarelli, E. Pericolini, E. Gabrielli et al., "Elucidating the immunological function of the Cryptococcus neoformans capsule," Future Microbiology, vol. 8, no. 9, pp. 1107-1116, 2013.

[27] M. Feldmesser, S. Tucker, and A. Casadevall, "Intracellular parasitism of macrophages by Cryptococcus neoformans," Trends in Microbiology, vol. 9, no. 6, pp. 273-278, 2001.

[28] C. M. Leopold Wager, C. R. Hole, K. L. Wozniak, and F. L. Wormley, "Cryptococcus and phagocytes: complex interactions that influence disease outcome," Frontiers in Microbiology, vol. 7, 2016.

[29] M. J. Davis, A. J. Eastman, Y. Qiu et al., “Cryptococcus neoformans- induced macrophage lysosome damage crucially contributes to fungal virulence," Journal of Immunology, vol. 194, no. 5, pp. 2219-2231, 2015.

[30] K. Voelz and R. C. May, "Cryptococcal interactions with the host immune system," Eukaryotic Cell, vol. 9, no. 6, pp. 835-846, 2010.

[31] S. M. Levitz, S. H. Nong, K. F. Seetoo, T. S. Harrison, R. A. Speizer, and E. R. Simons, "Cryptococcus neoformans resides in an acidic phagolysosome of human macrophages," Infection and Immunity, vol. 67, no. 2, pp. 885-890, 1999.

[32] L. M. Smith, E. F. Dixon, and R. C. May, "The fungal pathogenCryptococcus neoformansmanipulates macrophage phagosome maturation," Cellular Microbiology, vol. 17, no. 5, pp. 702-713, 2015.

[33] A. S. Gilbert, R. T. Wheeler, and R. C. May, "Fungal pathogens: survival and replication within macrophages," Cold Spring Harbor Perspectives in Medicine, vol. 5, no. 7, p. a019661, 2015.

[34] T. B. Kechichian, J. Shea, and M. Del Poeta, "Depletion of alveolar macrophages decreases the dissemination of a glucosylceramide-deficient mutant of Cryptococcus neoformans in immunodeficient mice," Infection and Immunity, vol. 75, no. 10, pp. 4792-4798, 2007.

[35] M. Alvarez and A. Casadevall, "Phagosome extrusion and host-cell survival after Cryptococcus neoformans phagocytosis by macrophages," Current Biology, vol. 16, no. 21, pp. 2161$2165,2006$.

[36] H. Ma, J. E. Croudace, D. A. Lammas, and R. C. May, "Expulsion of live pathogenic yeast by macrophages," Current Biology, vol. 16, no. 21, pp. 2156-2160, 2006.

[37] F. Real, P. T. V. Florentino, L. C. Reis et al., "Cell-to-cell transfer of Leishmania amazonensis amastigotes is mediated by immunomodulatory LAMP-rich parasitophorous extrusions," Cellular Microbiology, vol. 16, no. 10, pp. 1549-1564, 2014.

[38] J. M. Bain, L. E. Lewis, B. Okai, J. Quinn, N. A. R. Gow, and L. P. Erwig, "Non-lytic expulsion/exocytosis of Candida 
albicans from macrophages," Fungal Genetics and Biology, vol. 49, no. 9, pp. 677-678, 2012.

[39] T. Bergsbaken, S. L. Fink, and B. T. Cookson, "Pyroptosis: host cell death and inflammation," Nature Reviews. Microbiology, vol. 7, no. 2, pp. 99-109, 2009.

[40] T. Bergsbaken, S. L. Fink, A. B. den Hartigh, W. P. Loomis, and B. T. Cookson, "Coordinated host responses during pyroptosis: caspase-1-dependent lysosome exocytosis and inflammatory cytokine maturation," Journal of Immunology, vol. 187 , no. 5, pp. 2748-2754, 2011.

[41] I. Jorgensen and E. A. Miao, "Pyroptotic cell death defends against intracellular pathogens," Immunological Reviews, vol. 265, no. 1, pp. 130-142, 2015.

[42] S. K. Vanaja, V. A. K. Rathinam, and K. A. Fitzgerald, "Mechanisms of inflammasome activation: recent advances and novel insights," Trends in Cell Biology, vol. 25, no. 5, pp. 308-315, 2015.

[43] F. Martinon, A. Mayor, and J. Tschopp, "The inflammasomes: guardians of the body," Annual Review of Immunology, vol. 27, no. 1, pp. 229-265, 2009.

[44] F. L. van de Veerdonk, L. A. B. Joosten, P. J. Shaw et al., "The inflammasome drives protective Th1 and Th17 cellular responses in disseminated candidiasis," European Journal of Immunology, vol. 41, no. 8, pp. 2260-2268, 2011.

[45] A. H. Tavares, P. H. Bürgel, and A. L. Bocca, "Turning up the heat: inflammasome activation by fungal pathogens," PLoS Pathogens, vol. 11, no. 7, article e1004948, 2015.

[46] O. Gross, H. Poeck, M. Bscheider et al., "Syk kinase signalling couples to the Nlrp3 inflammasome for anti-fungal host defence," Nature, vol. 459, no. 7245, pp. 433-436, 2009.

[47] A. G. Hise, J. Tomalka, S. Ganesan et al., "An essential role for the NLRP3 inflammasome in host defense against the human fungal pathogen Candida albicans," Cell Host \& Microbe, vol. 5, no. 5, pp. 487-497, 2009.

[48] N. Saïd-Sadier, E. Padilla, G. Langsley, and D. M. Ojcius, "Aspergillus fumigatus stimulates the NLRP3 inflammasome through a pathway requiring ROS production and the Syk tyrosine kinase," PLoS One, vol. 5, no. 4, article e10008, 2010.

[49] A. H. Tavares, K. G. Magalhães, R. D. N. Almeida, R. Correa, P. H. Burgel, and A. L. Bocca, "NLRP3 inflammasome activation by Paracoccidioides brasiliensis," PLoS Neglected Tropical Diseases, vol. 7, no. 12, article e2595, 2013.

[50] R. J. A. de Castro, I. M. Siqueira, M. S. Jerônimo et al., “The major chromoblastomycosis etiologic agent Fonsecaea pedrosoi activates the NLRP3 inflammasome," Frontiers in Immunology, vol. 8, p. 8, 2017.

[51] L. Mao, L. Zhang, H. Li et al., "Pathogenic fungus Microsporum canis activates the NLRP3 inflammasome," Infection and Immunity, vol. 82, no. 2, pp. 882-892, 2014.

[52] G. Lei, M. Chen, H. Li et al., "Biofilm from a clinical strain of Cryptococcus neoformans activates the NLRP3 inflammasome," Cell Research, vol. 23, no. 7, pp. 965-968, 2013.

[53] C. Guo, M. Chen, Z. Fa et al., “Acapsular Cryptococcus neoformans activates the NLRP3 inflammasome," Microbes and Infection, vol. 16, no. 10, pp. 845-854, 2014.

[54] M. Chen, Y. Xing, A. Lu et al., "Internalized Cryptococcus neoformans activates the canonical caspase- 1 and the noncanonical caspase-8 inflammasomes," Journal of Immunology, vol. 195, no. 10, pp. 4962-4972, 2015.

[55] J. P. Wang, C. K. Lee, A. Akalin, R. W. Finberg, and S. M. Levitz, "Contributions of the MyD88-dependent receptors
IL-18R, IL-1R, and TLR9 to host defenses following pulmonary challenge with Cryptococcus neoformans," PLoS One, vol. 6, no. 10, article e26232, 2011.

[56] M. Shourian, B. Ralph, I. Angers, D. C. Sheppard, and S. T. Qureshi, "Contribution of IL-1RI signaling to protection against Cryptococcus neoformans 52D in a mouse model of infection," Frontiers in Immunology, vol. 8, p. 19, 2018.

[57] S. Frases, B. Pontes, L. Nimrichter, N. B. Viana, M. L. Rodrigues, and A. Casadevall, "Capsule of Cryptococcus neoformans grows by enlargement of polysaccharide molecules," Proceedings of the National Academy of Sciences of the United States of America, vol. 106, no. 4, pp. 1228-1233, 2009.

[58] P. Albuquerque, A. M. Nicola, E. Nieves et al., "Quorum sensing-mediated, cell density-dependent regulation of growth and virulence in Cryptococcus neoformans," MBio, vol. 5, no. 1, article e00986, 2013.

[59] M. L. Rodrigues, L. Nimrichter, D. L. Oliveira et al., "Vesicular polysaccharide export in Cryptococcus neoformans is a eukaryotic solution to the problem of fungal trans-cell wall transport," Eukaryotic Cell, vol. 6, no. 1, pp. 48-59, 2007.

[60] A. Casadevall, W. Cleare, M. Feldmesser et al., "Characterization of a murine monoclonal antibody to Cryptococcus neoformans polysaccharide that is a candidate for human therapeutic studies," Antimicrobial Agents and Chemotherapy, vol. 42, no. 6, pp. 1437-1446, 1998.

[61] R. A. Bryan, O. Zaragoza, T. Zhang, G. Ortiz, A. Casadevall, and E. Dadachova, "Radiological studies reveal radial differences in the architecture of the polysaccharide capsule of Cryptococcus neoformans," Eukaryotic Cell, vol. 4, no. 2, pp. $465-475,2005$.

[62] L. Nimrichter, S. Frases, L. P. Cinelli et al., "Self-aggregation of Cryptococcus neoformans capsular glucuronoxylomannan is dependent on divalent cations," Eukaryotic Cell, vol. 6, no. 8, pp. 1400-1410, 2007.

[63] G. d. S. Araujo, F. L. Fonseca, B. Pontes et al., "Capsules from pathogenic and non-pathogenic Cryptococcus spp. manifest significant differences in structure and ability to protect against phagocytic cells," PLoS One, vol. 7, no. 1, article e29561, 2012.

[64] A. Alanio, M. Desnos-Ollivier, and F. Dromer, "Dynamics of Cryptococcus neoformans-macrophage interactions reveal that fungal background influences outcome during cryptococcal meningoencephalitis in Humans," MBio, vol. 2, no. 4, pp. 1-10, 2011.

[65] Y.-M. Kim, B. J. Schmidt, A. S. Kidwai et al., "Salmonella modulates metabolism during growth under conditions that induce expression of virulence genes," Molecular BioSystems, vol. 9, no. 6, pp. 1522-1534, 2013.

[66] K. Hiller, J. Hangebrauk, C. Jäger, J. Spura, K. Schreiber, and D. Schomburg, "MetaboliteDetector: comprehensive analysis tool for targeted and nontargeted GC/MS based metabolome analysis," Analytical Chemistry, vol. 81, no. 9, pp. 3429-3439, 2009.

[67] T. Kind, G. Wohlgemuth, D. Y. Lee et al., "FiehnLib: mass spectral and retention index libraries for metabolomics based on quadrupole and time-of-flight gas chromatography/mass spectrometry," Analytical Chemistry, vol. 81, no. 24, pp. 10038-10048, 2009.

[68] J. Xia, I. V. Sinelnikov, B. Han, and D. S. Wishart, "MetaboAnalyst 3.0-making metabolomics more meaningful," Nucleic Acids Research, vol. 43, no. W1, pp. W251-W257, 2015. 
[69] S. L. Fink and B. T. Cookson, "Caspase-1-dependent pore formation during pyroptosis leads to osmotic lysis of infected host macrophages," Cellular Microbiology, vol. 8, no. 11, pp. 1812-1825, 2006.

[70] A. C. Herring, J. Lee, R. A. McDonald, G. B. Toews, and G. B. Huffnagle, "Induction of interleukin-12 and gamma interferon requires tumor necrosis factor alpha for protective T1-cell-mediated immunity to pulmonary Cryptococcus neoformans infection," Infection and Immunity, vol. 70, no. 6, pp. 2959-2964, 2002.

[71] E. W. van Etten, N. E. van de Rhee, K. M. van Kampen, and I. A. J. M. Bakker-Woudenberg, "Effects of amphotericin B and fluconazole on the extracellular and intracellular growth of Candida albicans," Antimicrobial Agents and Chemotherapy, vol. 35, no. 11, pp. 2275-2281, 1991.

[72] D. C. McFadden, M. de Jesus, and A. Casadevall, "The physical properties of the capsular polysaccharides from Cryptococcus neoformans suggest features for capsule construction," The Journal of Biological Chemistry, vol. 281, no. 4, pp. 1868-1875, 2006.

[73] I. Morita, M. Kawamoto, and H. Yoshida, "Difference in the concentration of tryptophan metabolites between maternal and umbilical foetal blood," Journal of Chromatography. B, Biomedical Sciences and Applications, vol. 576, no. 2, pp. 334-339, 1992.

[74] S. Gilbert, J. Xu, K. Acosta, A. Poulev, S. Lebeis, and E. Lam, "Bacterial production of indole related compounds reveals their role in association between duckweeds and endophytes," Frontiers in Chemistry, vol. 6, p. 265, 2018.

[75] S. Moretti, S. Bozza, V. Oikonomou et al., "IL-37 inhibits inflammasome activation and disease severity in murine aspergillosis," PLoS Pathogens, vol. 10, no. 11, article e1004462, 2014.

[76] H. H. Shen, Y. X. Yang, X. Meng et al., "NLRP3: a promising therapeutic target for autoimmune diseases," Autoimmunity Reviews, vol. 17, no. 7, pp. 694-702, 2018.

[77] C. L. Evavold, J. Ruan, Y. Tan, S. Xia, H. Wu, and J. C. Kagan, "The pore-forming protein gasdermin D regulates interleukin-1 secretion from living macrophages," Immunity, vol. 48, no. 1, pp. 35-44.e6, 2018.

[78] T. Liu, Y. Yamaguchi, Y. Shirasaki et al., "Single-cell imaging of caspase-1 dynamics reveals an all-or-none inflammasome signaling response," Cell Reports, vol. 8, no. 4, pp. 974-982, 2014.

[79] S. P. Cullen, C. J. Kearney, D. M. Clancy, and S. J. Martin, "Diverse activators of the NLRP3 inflammasome promote IL-1 $\beta$ secretion by triggering necrosis," Cell Reports, vol. 11, no. 10, pp. 1535-1548, 2015.

[80] J. M. Sanz and F. D. Virgilio, "Kinetics and mechanism of ATP-dependent IL-1 $\beta$ release from microglial cells," Journal of Immunology, vol. 164, no. 9, pp. 4893-4898, 2000.

[81] Z. Zasłona, E. M. Pålsson-McDermott, D. Menon et al., "The induction of pro-IL- $1 \beta$ by lipopolysaccharide requires endogenous prostaglandin E2Production," Journal of Immunology, vol. 198, no. 9, pp. 3558-3564, 2017.

[82] E. J. Folco, G. K. Sukhova, T. Quillard, and P. Libby, "Moderate hypoxia potentiates interleukin- $\beta$ production in activated human macrophages," Circulation Research, vol. 115, no. 10, pp. 875-883, 2014.

[83] S.-C. Cheng, F. L. van de Veerdonk, M. Lenardon et al., “The dectin-1/inflammasome pathway is responsible for the induction of protective T-helper 17 responses that discriminate between yeasts and hyphae of Candida albicans," Journal of Leukocyte Biology, vol. 90, no. 2, pp. 357-366, 2011.

[84] M. Wellington, K. Koselny, F. S. Sutterwala, and D. J. Krysan, "Candida albicans triggers NLRP3-mediated pyroptosis in macrophages,” Eukaryotic Cell, vol. 13, no. 2, pp. 329-340, 2014.

[85] L. Kasper, A. König, P.-A. Koenig et al., "The fungal peptide toxin Candidalysin activates the NLRP3 inflammasome and causes cytolysis in mononuclear phagocytes," Nature Communications, vol. 9, no. 1, p. 4260, 2018.

[86] T. R. O’Meara, K. Duah, C. X. Guo et al., "High-throughput screening identifies genes required forCandida albicansInduction of macrophage pyroptosis," MBio, vol. 9, no. 4, 2018.

[87] S. Vylkova and M. C. Lorenz, "Phagosomal neutralization by the fungal pathogen Candida albicans induces macrophage pyroptosis," Infection and Immunity, vol. 85, no. 2, 2017.

[88] I. E. Brodsky, N. W. Palm, S. Sadanand et al., "A Yersinia effector protein promotes virulence by preventing inflammasome recognition of the type III secretion system," Cell Host \& Microbe, vol. 7, no. 5, pp. 376-387, 2010.

[89] D. Ratner, M. P. A. Orning, M. K. Proulx et al., “The Yersinia pestis effector YopM inhibits pyrin inflammasome activation," PLoS Pathogens, vol. 12, no. 12, article e1006035, 2016.

[90] D. J. Taxman, M. T.-H. Huang, and J. P.-Y. Ting, "Inflammasome inhibition as a pathogenic stealth mechanism," Cell Host \& Microbe, vol. 8, no. 1, pp. 7-11, 2010.

[91] A. S. Gilbert, P. I. Seoane, P. Sephton-Clark et al., "Vomocytosis of live pathogens from macrophages is regulated by the atypical MAP kinase ERK5," Science Advances, vol. 3, no. 8, article e1700898, 2017.

[92] M. Hilbert, L. M. Voll, Y. Ding, J. Hofmann, M. Sharma, and A. Zuccaro, "Indole derivative production by the root endophyte Piriformospora indicais not required for growth promotion but for biotrophic colonization of barley roots," The New Phytologist, vol. 196, no. 2, pp. 520-534, 2012.

[93] M. Gunasekaran, "Synthesis of tryptophol and indolelactic acid by Cryptococcus neoformans," Mycologia, vol. 72, no. 3, p. $578,1980$.

[94] T. Zelante, R. G. Iannitti, C. Cunha et al., "Tryptophan catabolites from microbiota engage aryl hydrocarbon receptor and balance mucosal reactivity via interleukin-22," Immunity, vol. 39, no. 2, pp. 372-385, 2013.

[95] G. Hu, P.-Y. Cheng, A. Sham, J. R. Perfect, and J. W. Kronstad, "Metabolic adaptation in Cryptococcus neoformans during early murine pulmonary infection," Molecular Microbiology, vol. 69, no. 6, pp. 1456-1475, 2008.

[96] M. S. Price, M. Betancourt-Quiroz, J. L. Price et al., "Cryptococcus neoformans requires a functional glycolytic pathway for disease but not persistence in the host," MBio, vol. 2, no. 3, 2011.

[97] K. F. C. Martho, A. T. de Melo, J. P. F. Takahashi et al., "Amino acid permeases and virulence in Cryptococcus neoformans," PLoS One, vol. 11, no. 10, article e0163919, 2016.

[98] E. E. McClelland, U. A. Ramagopal, J. Rivera et al., "A small protein associated with fungal energy metabolism affects the virulence of Cryptococcus neoformans in mammals," PLoS Pathogens, vol. 12, no. 9, article e1005849, 2016. 
[99] D. G. Perregaux, P. McNiff, R. Laliberte et al., "Identification and characterization of a novel class of interleukin-1 posttranslational processing inhibitors," The Journal of Pharmacology and Experimental Therapeutics, vol. 299, no. 1, pp. 187-197, 2001.

[100] R. C. Coll, A. A. B. Robertson, J. J. Chae et al., "A smallmolecule inhibitor of the NLRP3 inflammasome for the treatment of inflammatory diseases," Nature Medicine, vol. 21, no. 3, pp. 248-255, 2015. 